\title{
ANDROMACHI SENIORIS
} ANTIQVISSIMVM DE THERIACA CARMEN $A D$

\author{
IMPERATOREM NERONEM \\ RECVSVM OCCASIONE \\ THERIACAE RECENS PARATAE \\ IN OFFICINA LEINKERIANA.
}

NORIMBERGAE MDCCLIV.

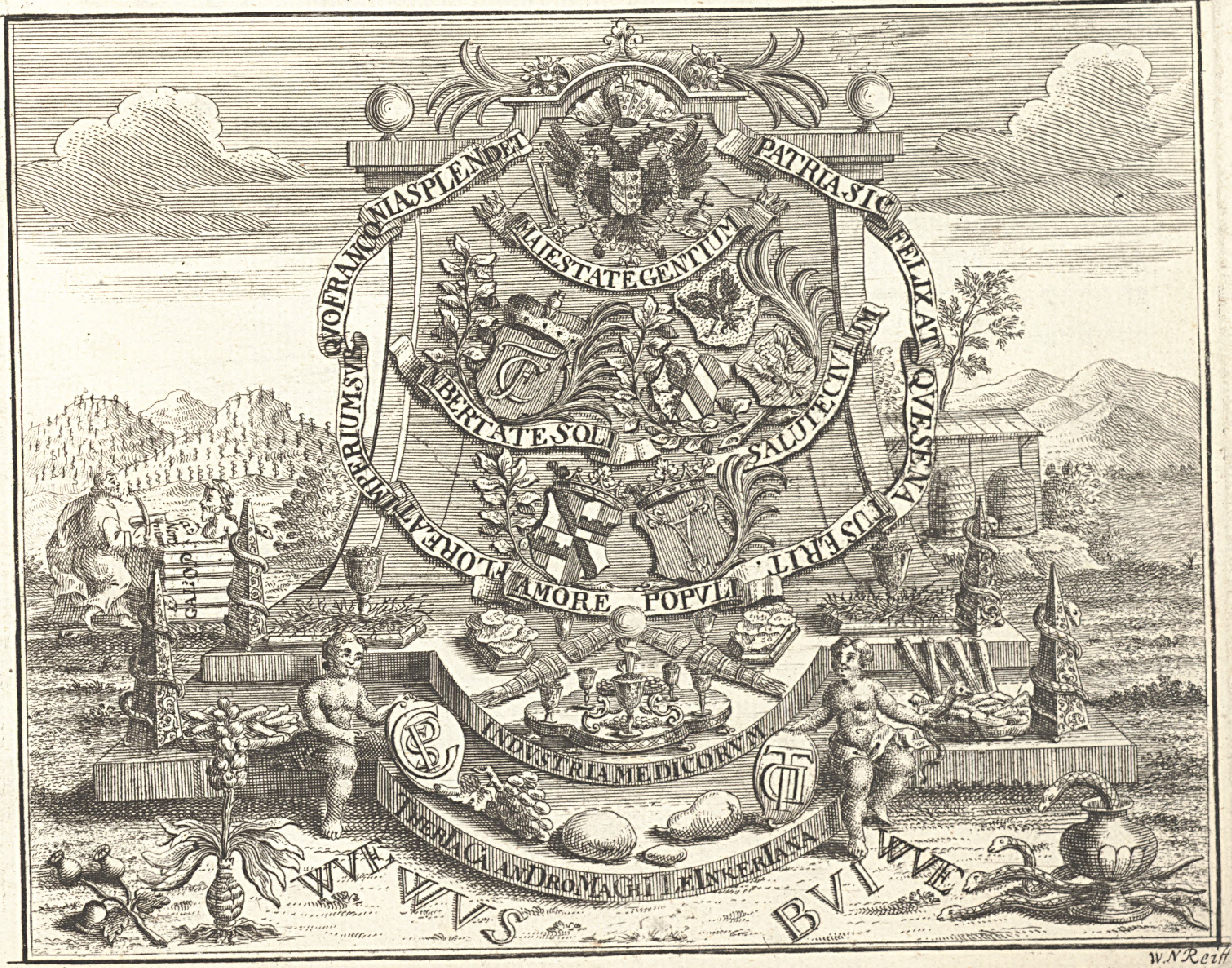



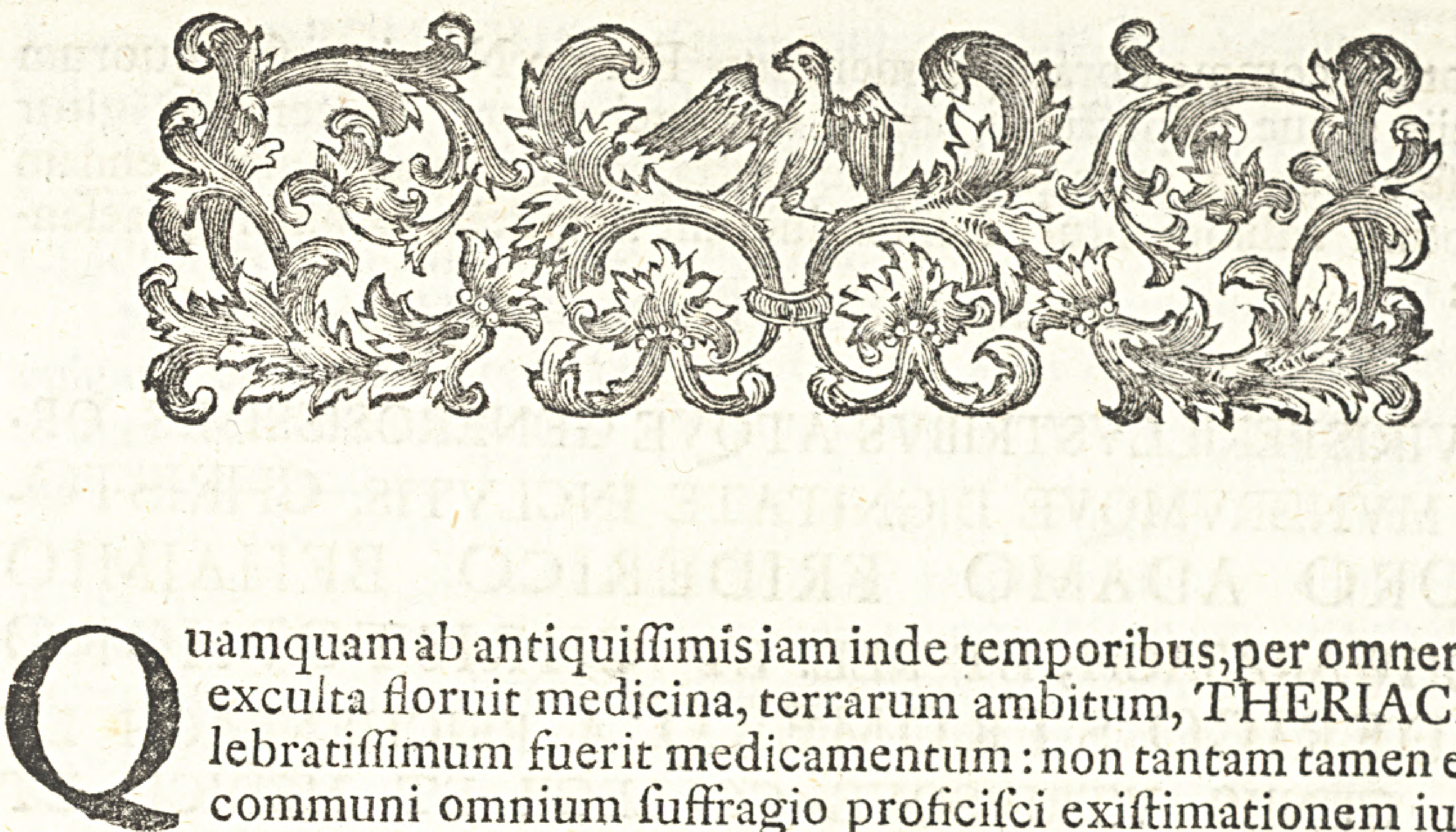
uamquam ab antiquiffimis iam inde temporibus, per omnem, ubi exculta floruit medicina, terrarum ambitum, 'THERIACA celebratiffimum fuerit medicamentum: non tantam tamen eius a communi omnium fuffragio proficifci exiftimationem iudicamus; quantam ab illuftri fuo auktore eminentiori quodam iure fibi vindicauit. Vtut enim plurimi, iique artis medicae peritiffimi fuerint uiri, qui adverfus ferpentium ictus uenenorumque infidias uaria medicamina excogitarunt: illa tamen ANDROMACHI THERIACA, omnes aliorum conatus tanto poft fe interuallo reliquit, ut, quam primum dedica. tione facta ad IMPERATORIS olim NERONIS folium inclaruit, ftatim in omne genus hominum dimanarit. Qua de re mihi praeftantiam eiusdem declaraturo inftar omnium erit Auctoris ANDROMACHI SENIORIS carmen de 'THERIACA ad eundem Imperatorem fuperftes, quod omnem inftituti paginam abfoluere eo magis quidem videtur, quo uberius 'Theriaces virtutes, compofitionemque explicat, quoque rarius illud quis infpiciet, nifi Galenica fcripta nocturna, diurnaque manu verfare confueuerit.

Poftulat vero praeuiam hac de re cognitionem, ne prorfus imparata accedat pectantium copia, folemnis quidam actus, quo iam confueto pharmaceuticarum vifitationum tempore 'THERIACAM more maiorum difpenfandam fulcepit VIR PRAESTAN'TISSIMVS PAV. LVS CANV'TVS LEINKER, qui cum VRBIS CIVIBVS, tum CELSISSIMORVM LAVDATISSIMORVMQVE FRANCONIAE OR. DINVM copiis militaribus rem pharmaceuticam procurat.

Quemadmodum autem olim, apud Quirites praefertim, nihil praeclari, egregiique gerebatur, quod non Confulum memoria pofteritati commendatum fuerit: ita et in rariori hac, in foro medico occupatioA 2 ne, 
ne, notari, commemorarique merentur Eorum Nomina, fub quorum aufpiciis atque infpectione omnia tranfigebantur. Pulcerrimo igitur inter fe apparatu, miroque ordine iuncta, antequam ad commifcendam antidotum adhiberentur, exfplenduerunt fimplicia, ex officio praelenribus:

VIRIS PERILLVSTRIBVS ATQVE GENEROSISSIMIS, ORTV, MVNERVMQVE DIGNITA'TE INCLVTIS, CHRISTO. PHORO ADAMO FRIDERICO BEHAIMIO A SCHWARZBACH, ET REL. ET CHRISTOPHORO FRIDERICO STROMERO A REICHENBACH ET REL. GENIIS V'TRIVSQVE COLLEGII ET MEDICI, ET PHARMACEV'TICI 'TVTELARIBVS.

MEDICINAE DOCTORIBVS vero VIRIS ILLVS'TRIBVS, EXCELLEN'TISSIMIS atque EXPERIEN'TISSIMIS,

CHRIS'TOPH. LVD. GOECKELIO Seniori Collegii Primario. CHRIS'TOPH. ANDR. WINCKLERO Vifitatore Seniori. CHRISTOPH. IACOBO 'TREVVIO Decano h.t. Spectatiffimo. 10. CONRADO WITVVERO Vifitatore extra ordinem.

IO. VVILHELMO VVIDMANNO Vifitatore extra ordinem. 10. ADAMO BAVERO Vifitatore Iuniori.

Poffem iam in numerofiffimas circa colligenda ingredientia curas excurrere. Poffem in confiderandis, praeeunte aenea Frontifpicii tabula, ornamentis verfari, nifi anguftum Chartae fpatium; nifi importu. na a fcopo aberratio; et nifi denique iufta Fratris germani talia enarrantis modeftia prohiberent. Dicendum potius mihi erit de ifta $A N$ DROMACHI ELEGIA, quam dudum a me latino veftitu indutam; nunc vero tempori adaptandam, preloque committendam video. $\mathrm{Vt}$ yero etiam hac in re commoda differendi capiam primordia, ipfum ANDROMACHVM noftrum ab aliis paucis dignofeere, a praefenti inftituto non prorfus alienum videtur.

Perfpicuitatis id iubet ratio, quum BAELIVS praefertim in DiCtionario fuo hiftorico-critico praeter hunc noftum quinque alios nos do. 
doceat ANDROMACHOS. Quos inter quidam fuit Siculus TIMAEI hiftoriographi Pater, quidam fub ALEXANDRI M. exercitu; alius SELEVCI CALLINICI Regis Syriae affinis; alius CRASSI, ROMANORVMQVE indignum mentione nomen, proditor; alius fub DIOCLETIANO in Nicomedia Sophifta.

Nofter vero ANDROMACHVS - Creta oriundus fuit. Vir haud vulgaris eruditionis, tefte GALENO, qui artis fuae experientiam multa cum facundia coniunxit. Praeter celebre, quod ex variis fcriptis ** adeptus eft nomen, 'THERIACAE AVCTOR, qui MI'THRIDA'TIO nonnullis ademptis, nonnullis additis rebus, -Viperas unde nomen, adiecit, quamvis ipfe GALENEN hanc fuam medicinam appellaverit. Tam felici fortis conditione ufus erat, ut non folum amicorum fuorum cultu digniffimus haberetur ; Ted etiam ad fummum honoris faftigium arte fua eveetus fuerit. Huius rei luculentum eft teftimonium ipfius, qua aliis praefulfit dignitas; quaque ipfi munus primi inter NERONIS medicos tueri licuit, primusque omnium, tefte CLERICO, Archiater, MAGNVSque fuitappellatus. *** Illius autem documentum eft EROTIANI in illum obfervantia, qua Lexicon fuum eius nomini infcripfit. Cum vero eum, tamquam Inventorem 'THERIACES confideramus, affirmare licebit, eius cum CAESARE Confuetudinem communi Societati Afclepiadeae tum propitiam fuife: eo, quod Principi tanto, aufpicatiffimo confilio, eiusmodi remedium commendaret, fuaeque arti non parum inde honoris conciliaret. Quum enim ab exemplis non leuis petatur audtoritas, fieri aliter non potuit, quin medicicina ab ipfo CAESARE adhibita in maiorem indies fidem abierit, ufumque fuum per fecula amplifieauerit. Mirari proinde etiam non fas eft, quod, cum ANDROMACHVS fui memoriam defcriptione huius medicaminis ab obliuione vindicauerit, etiam alii idem haud intentatum reA 3

lique-

* Vid. Baelivs 1, c. fub, V. Andromachi, Voffius de Philor, Cap, XII, Stollius in Hift, Med, Cap. I. \$. 78.

* Quamuis autores tantum libri de medicamentis ad affequs exteraos mentionem faciazt, ex collectis tamen Galeni locis patet, fcripfiffe eum librum Mnafonis dietum, aec non de virtutibus ad exteriora, de internarum affectionum curatione, de arteriacis confectionibus, de medicamentis, intra corpus affumendis, de confectionibus internis, ut varias alias ab ipfo editas compofitiones taceam. Conf. ANTONII MVSAE BRASAVOLI indicem in Galeni libros editionis infra cit. latina.

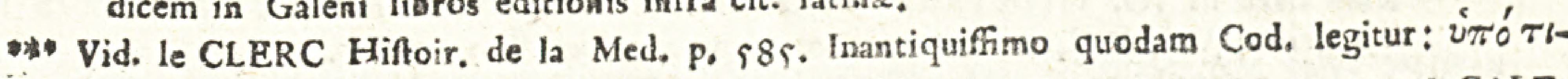

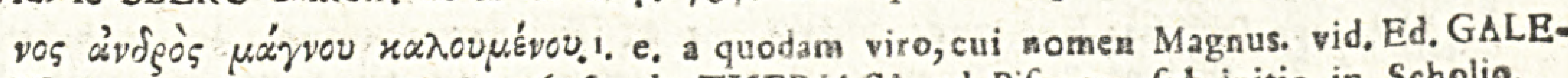
NI lat, ap. Juntas venet, 1586. L, de THERIACA ad Pifonem, fub initio in Scholio, 
liquerunt. Quorum alter DEMOCRATES erat, qui genere iambico Theriacam cecinit; alter vero ipfius ANDROMACHI Filius IV. NIOR dißus, qui oratione pedeftriantidoti huius praeparationem enodauit, explanauitque. Quem eo maiori cura notamus, quo facilius cum ANDROMACHO Patre confundi poterit. Quo fato ANDRO. MACHVS SENIOR ad Aftrologos relatus fuerit, erudite BAELIVS differit. Nos vero id, quum ad finem noftrum non faciat, lubenter praetermittimus.

Ad carmen ipfum properamus, ubi rationem nouae verfionis reddere jubemur. In verfione quamuis elegantiffima IVLII MARTIANI ROTAE * cum textu graeco nimirum collata, perfpexi, eam adeo liberali ftylo expreffam effe, ut graecum exemplum, aliam, fi quis auderet, omnino pateretur. Quantum enim interpres fuo luxuriatus fit ingenio, teftari poteft unicus ille verfus:

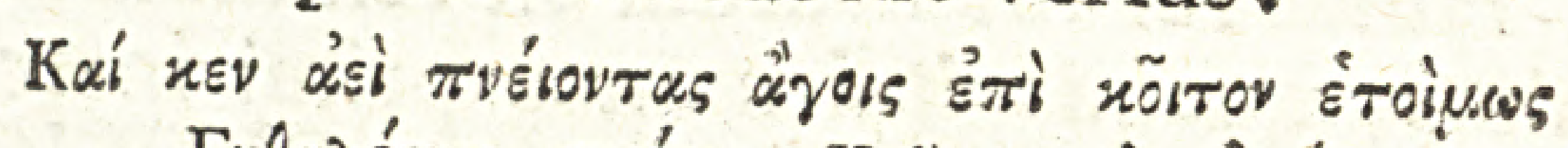

Quem ita vertit.

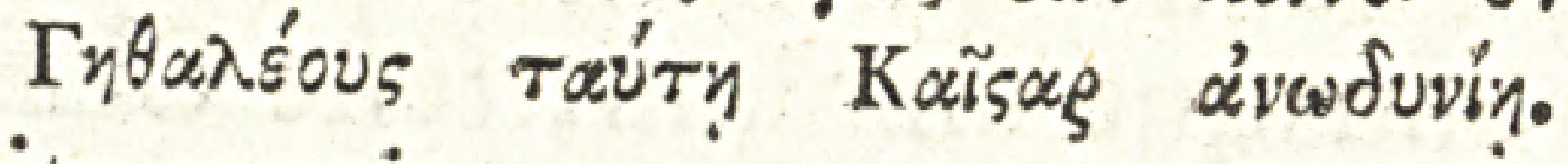

Haktenus, et pondus, viresque, et tempora Caefar, Quod fupereft, dicam quo facienda modo.

Aggreffus ergo fum laborem. Verum vix in eodem paullulum proueetus manum de tabula iterum detrahere conftitui, cum in HIPPOCRATIS et GALENI OPP. a RENATO CHAR'TERIO VINDOCINENSI Lutet. Parif: 1679. fplendidiffime editis alia verfio ** vultum noftrum fubierit, quae propius ad mentem auctoris accedit. At enim vero diutius illam mihi confideranti deinceps patuit, verfionem hanc non niff ufque ad verfum progredi: Inde quater ternas mutato pondere Dracbmas etc. Reliqua enim difticha eadem funt, quae in verfione IV. LII MARTIANI ROTAE leguntur. Vt ex eadem editione ubiutraque verfio pofita eft, elucefcit. Quare tantum abfuit, ut me ab eius rei continuatione deterreri paffus fim, ut illam potius nono ftudio ad calcem perduxerim. Quid in reliquis, dum brevis effe volo, verfiones inter fe differant, fedula quemuis collatio edocebit. Nihil interim magis equidem doleo; quam, quod illud exemplum in manus meas pervenire non potuit, unde IVLIVS MARTIANVS ROTA carmini integrum aliud Diftichon addere curauit, quodque latine ita reddidit: ***

- Edita cum GALENI edit. fupra cit. ap. Juntas.

In-

- Num haec fit JO. GVINTERII ANDERNACI verfio, cuius meminit FABRICIVS in Bibl. graeea Vol. XIII, p. 60 mihi equiden nondum fatis conftat.

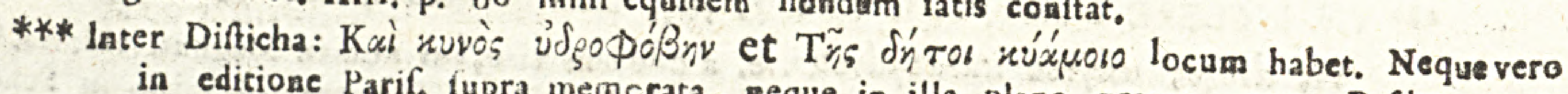
in editione Parif, fupra memcrata, neque in illa plane graeca. quae Bafilea 1538 . prodiit, neque denique in editione ALDINA. Venetiis $1929^{\circ}$ imprefla legitur, 
Infomnes demum quibus eft mos ducere noctes, Conciliat fomnum, pervigilesque leuat.

Quod autem ad dignitatem huius Poematis attinet, memoratu dignum eft, quod illud IO. 'TZE'TZES Chiliad. XII. hift. 397. ad indicandam GALENI ipfius aetatem, quum fcriptis illius bis * illatum fit, adhibeat.

Sub finem denique ne vacua relinquatur pagina, neque veterum compofitioni quid defit, HEDYCHROI confectionem ex Galeno adieci。**

Tantum ergo de antiquiffima hac materiam medicam fpectante Poefi, praefaminis loco afferendum effe duxi, relicta aliis ad graecas litteras lima critica. THERIACES compofitionem ipfam, quod attìnet, res ipfa omnium oculis fubiecta loqui videtur: Cum enim tanta, tamque nobilium rerum conftet copia, ut iure, meritoque fuo eam

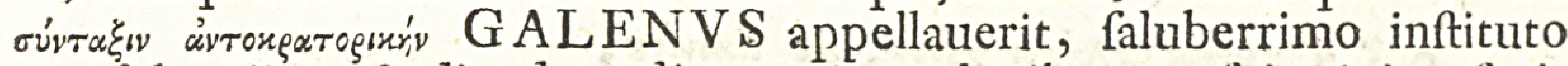
non folum iis cuftodienda traditur, qui arte, legibusque fuis ciuium fanitatem femper refpiciunt; fed etiam eiusdem conficiendae cura ac ratio publica MAGISTRATVS auctoritate approbatur. Ac eiusmodi quidem ritum non fine eximio antiquitatis exemplo condecorant medici, quum ipfe GALENVS *** huius antidoti praeparationi olim non folum faepiffime adeffet, fed et illam, iubente AN'TONINO, praeparaffet. 'Tanta enim veterum in condenda hac antidoto erat circumfpectio, ut in indaganda illius hiftoria fummæ induftriæ ab ipfis adhibitæ repetamus veftigia. Cuius tractationis ANDROMACHI haec defcriptio egregium nobis exhibet compendium. In primis cum metro inclufa fit, quo foriptionis genere **** veteres eo lubentius uff funt, quo tutius res ita ad Po. fteritatem conferuari polfe crediderunt.

* Lib, de Theriaca ad PISON, et Lib. I. de Antidocis。

** Ibidem de Antidotis L. I. Po m. ro4,

* GALENVS de antid. Lib, 1, p. m. 99. Versum qui Imperator antidozum laudabas a Demetrio medicorum primario confectam, eo vita functo, Euphrati medicae materiae venditori, a quo fimplices omnes medicinas ad Theriacam conficiendasen emebat, per literas fignificanit, us fibi renunciaret, quisnam wedicus imperatoriams antidotums conficsimti Demetrio affuifer. Ab eo itaque cum intellexiffet me femper Demetrio quoties theriacams componeros; aftetiffe, imm gividem osm me per literas componere Anioninus inffies.

20* Plinius VALERIANVS Lib. 30 c.57. et Lib, 4. c. 38. ait: THERIACAM apud Infulam COVM in tomplo $\triangle B S C V L A P I l$ incifam fuifte lapide, et reribus dedicatam, Conf, FABRICIVS l, $c_{0}$ 


\section{ANAPOMAXOY ПPECBYTEPOY $\Theta H P I A K H \quad \triangle I$ EXI@N@N}

H KAAOYMENH $\Gamma A \Lambda H N H$.

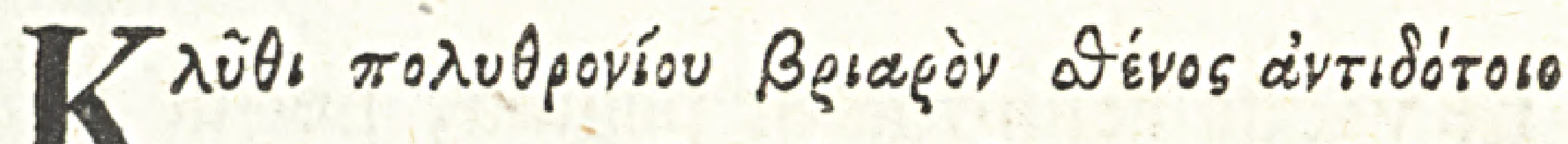

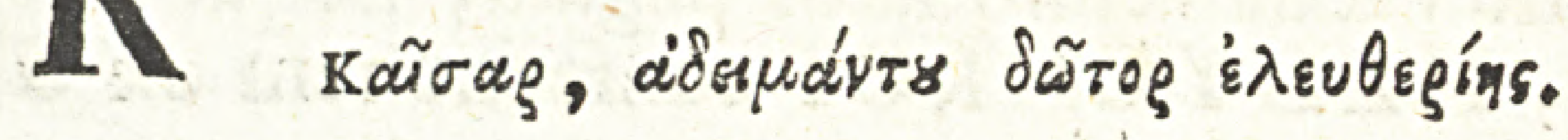

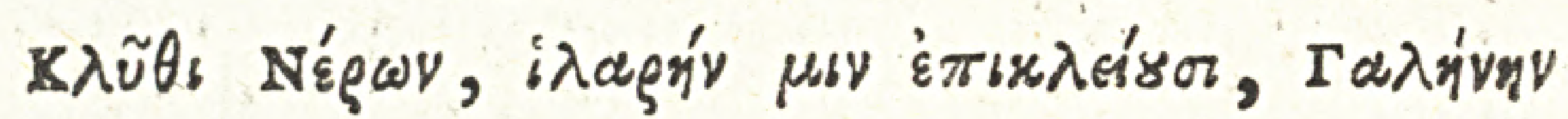

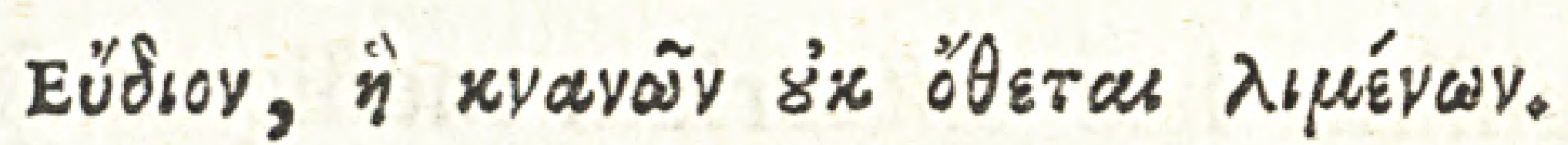

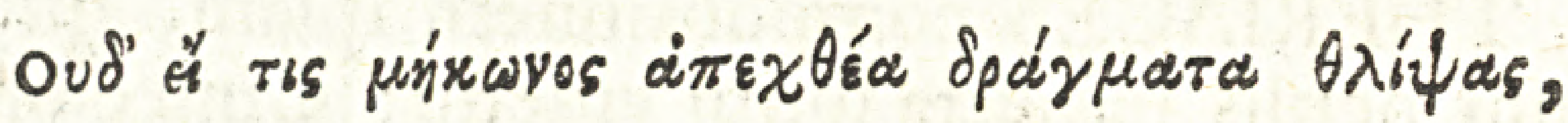

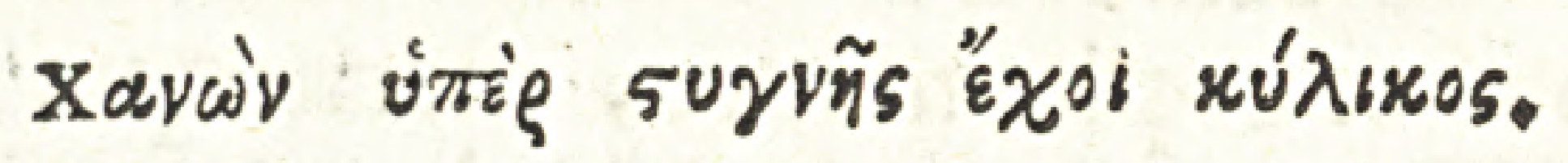

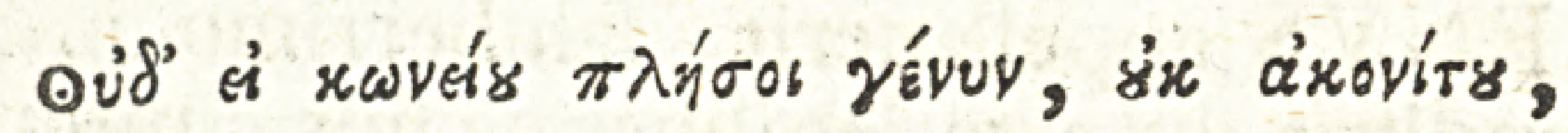

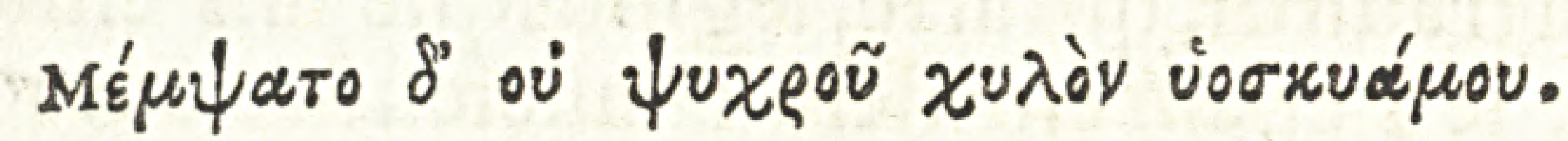

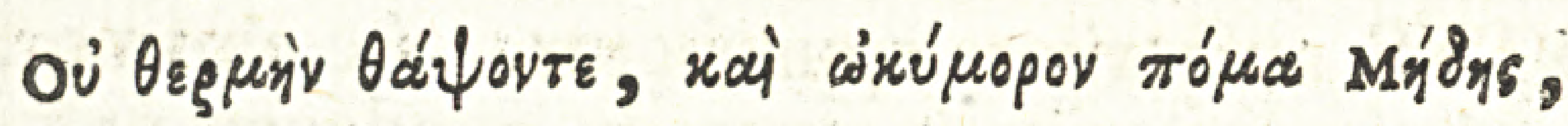

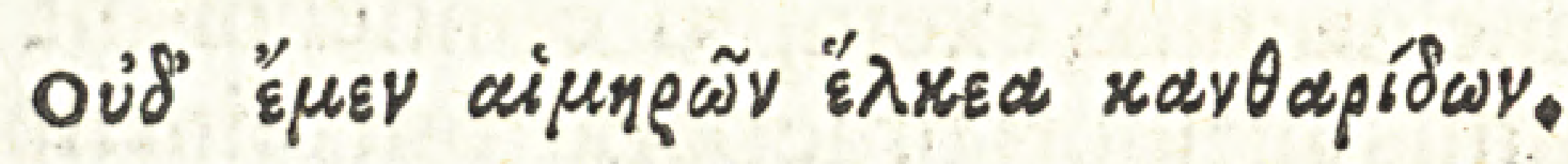

Oن ไ०

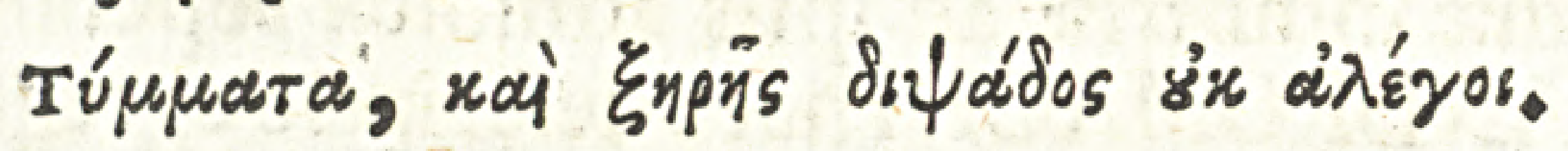

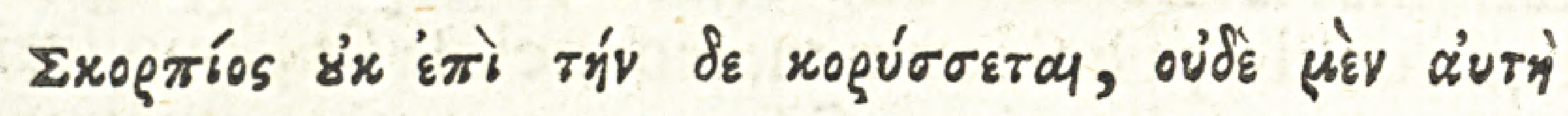

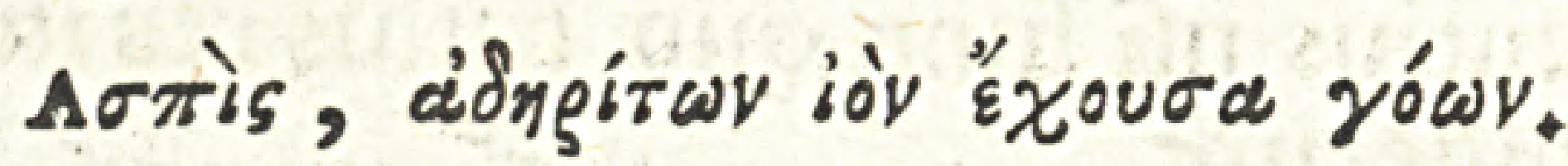

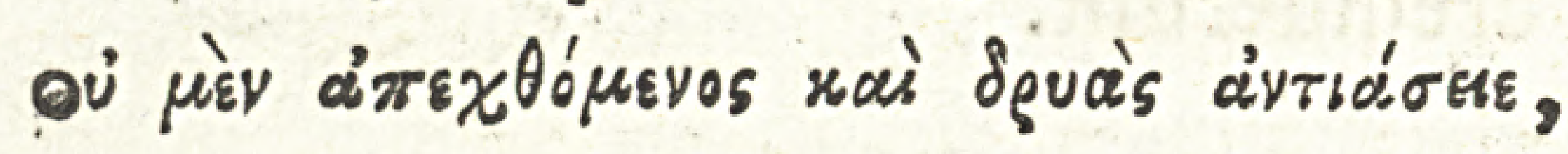

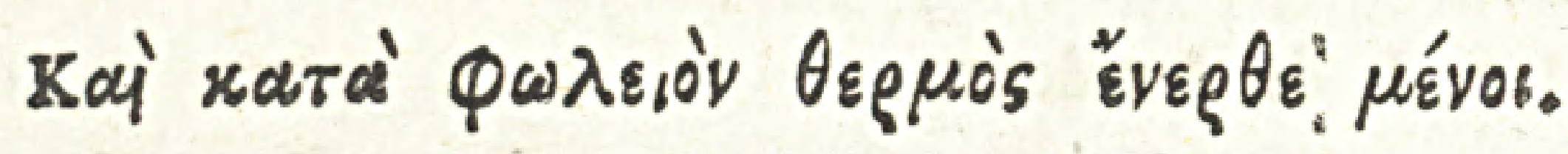

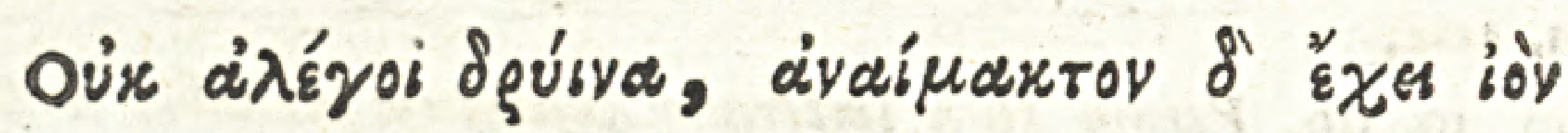

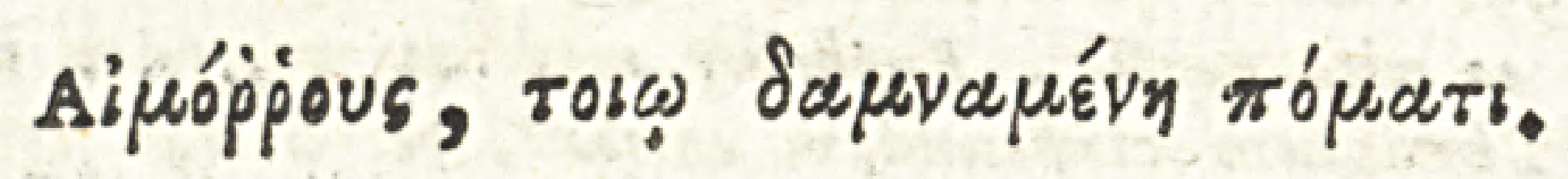

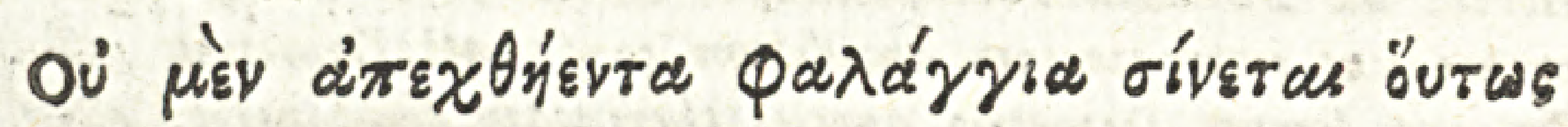

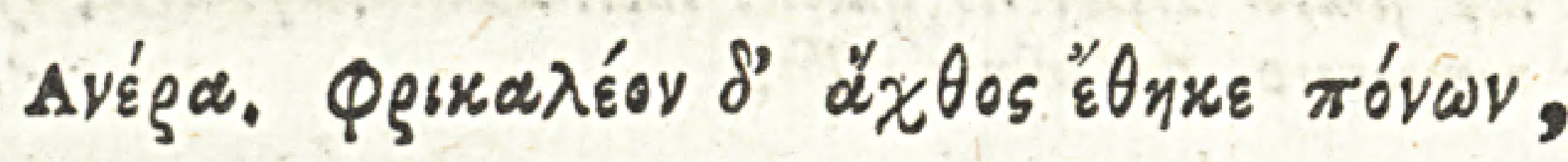

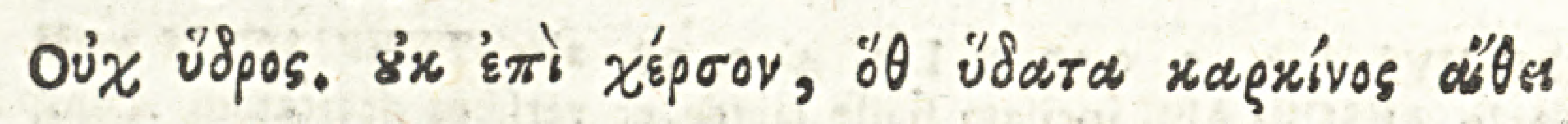

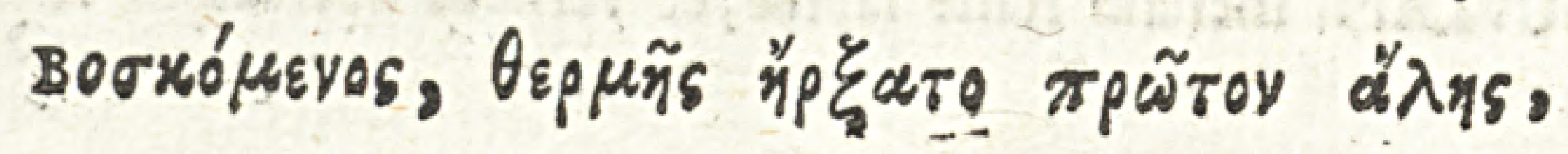




\section{ANDROMACHI SENIORIS THERIACE EX VIPERIS GALENE DICTA.}

Oux capit Antidoti tot pharmaca percipe robur, Súb quo libertas aurea, Cæfar, adeft. Nomina funt NERO hæc: Hilaris, Tranquilla, Serena, Cyaneos portus temnat ut illa, vide.

Non, fi fomniferum comprefferis ergo Papauer, Hinc tremebunda calix omnia mortis habet. Collue te fuccis, noceant Aconita, Cicutæ, Succus Hyofciami frigidulusque nihil. Quid feruens Thapfus, Medeæ Philtra veneni Condent? crudeles ulcere Cantharides?

Vipera non timeo tua, non tua dira, Cerafte, Vulnera, femper iners arida Dipfas abi. Scorpius arma negat, nec ineluctabile fatum Afpis ut anteacto tempore femper habet. Hoftis quique fuit Dryas nihil audeat, obftans,

Profundas latebras feruidus atque premat.

Quidue Dryina poteft? Hæmorrhois abfque cruore Virus habens, potu hoc fitque domanda fuo. Non ita mortales inuifa phalangia ladunt,

Nec morbi vires horripilantis habent. Non Hydrus, inque nouis terris, mare Cancer adurat, Pafcens, qui calidis fpumeus exit aquis: 


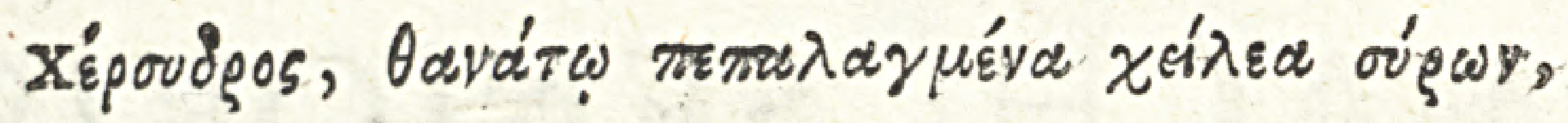

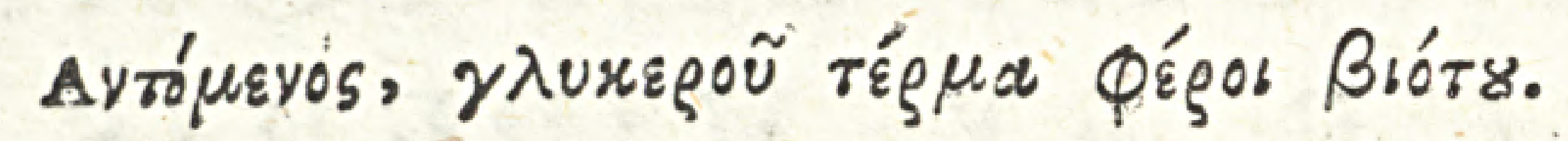

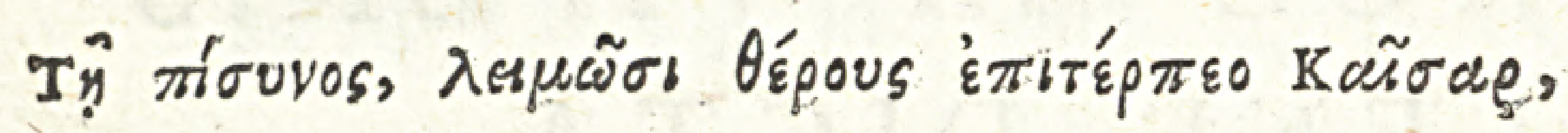

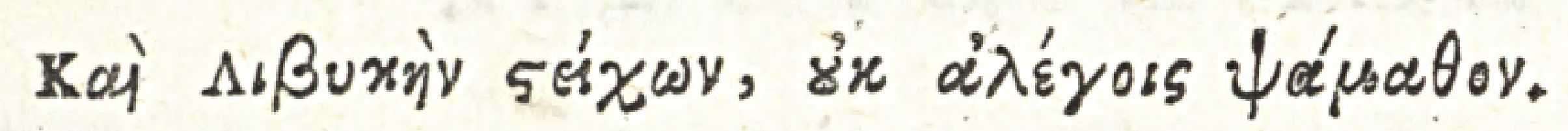

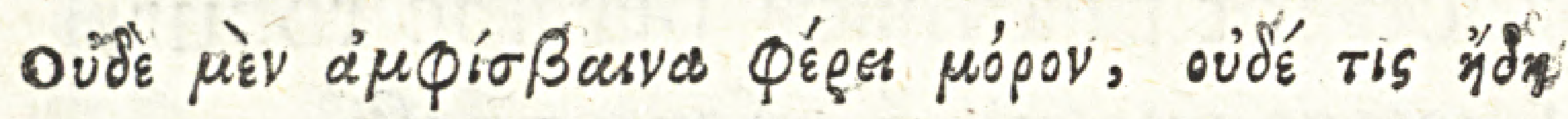

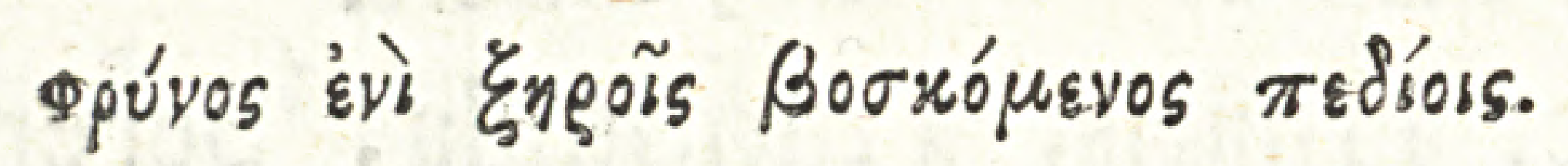

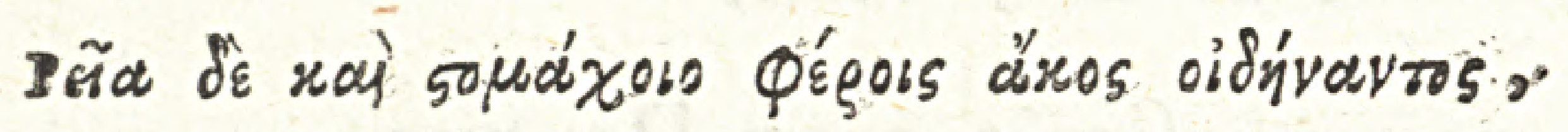

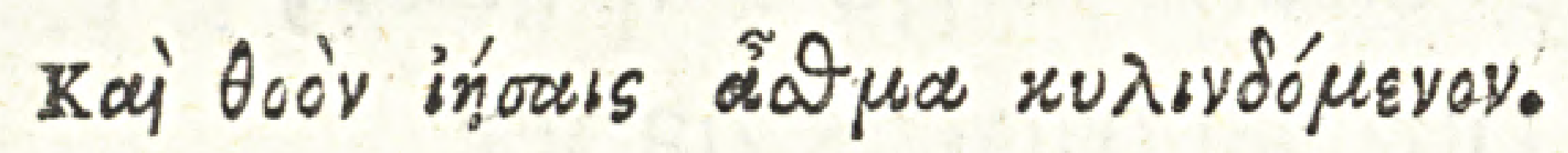

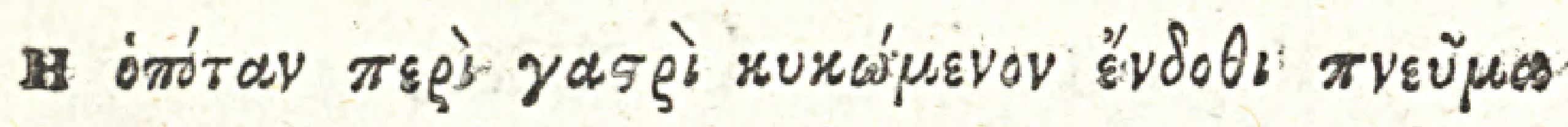

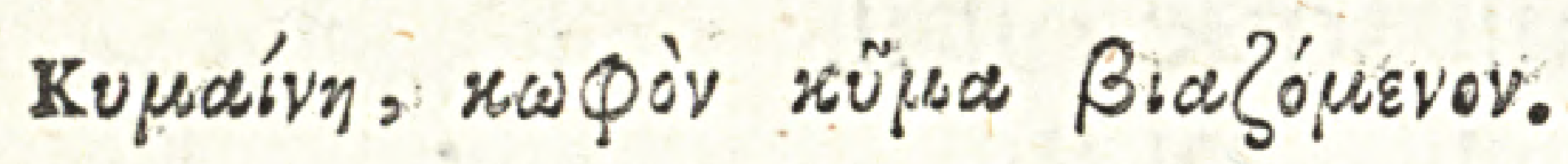

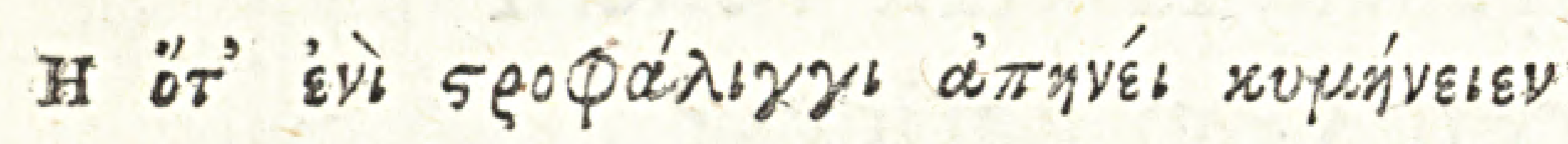

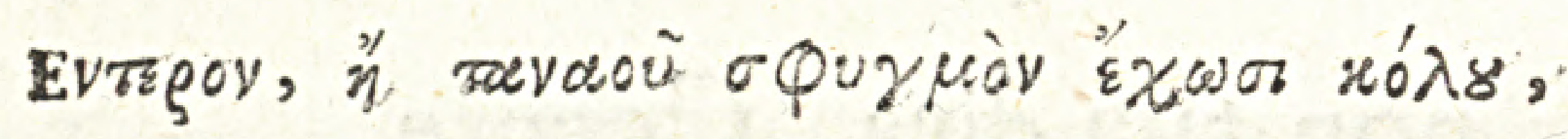

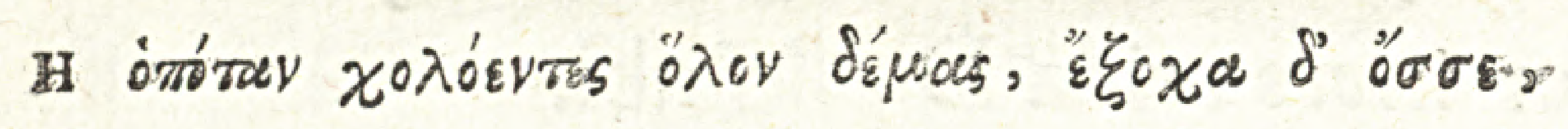

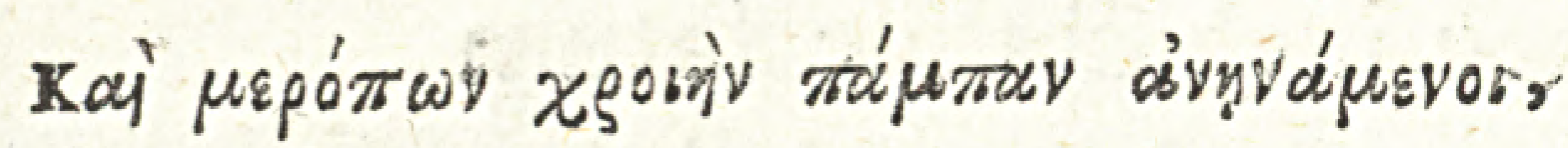

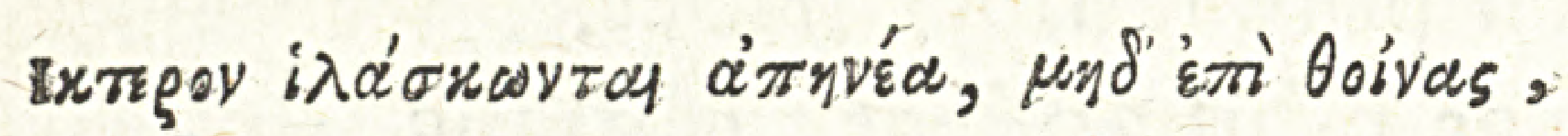

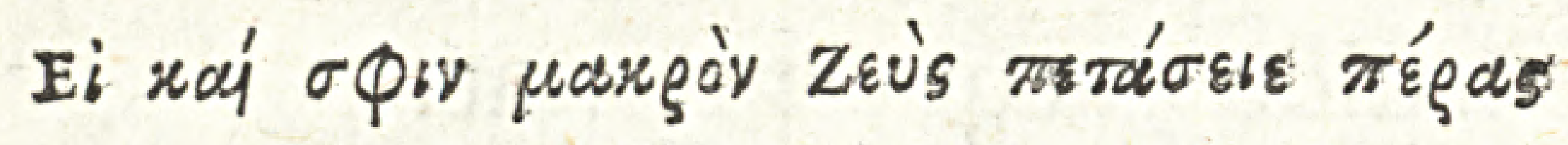

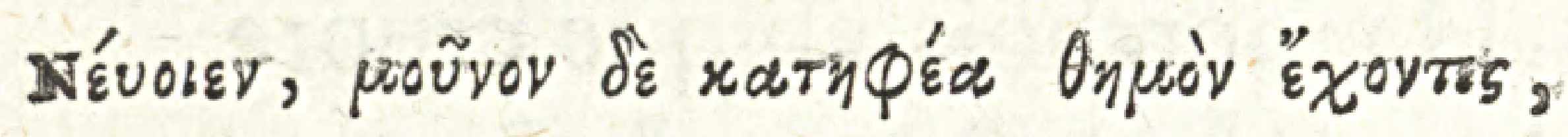

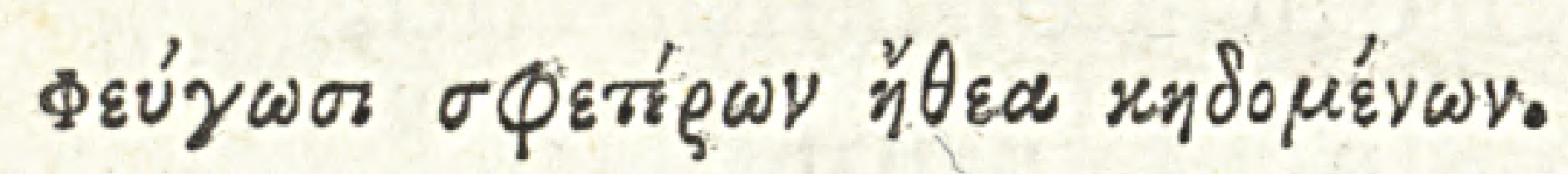

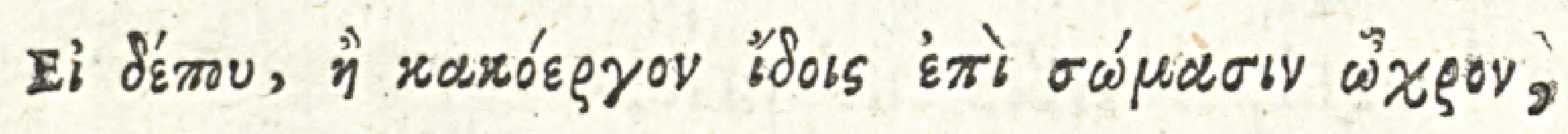

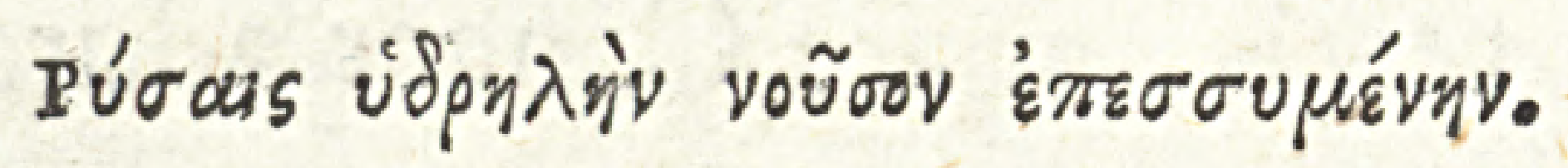

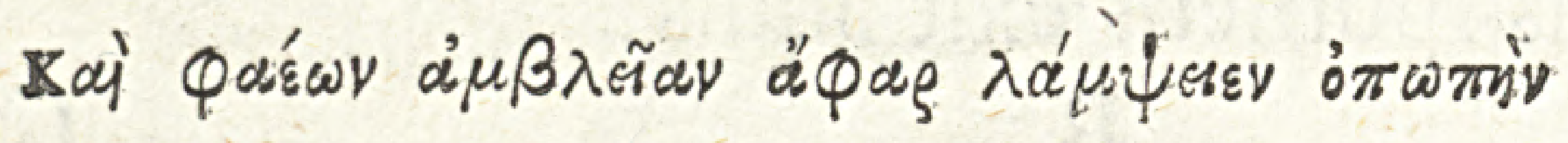

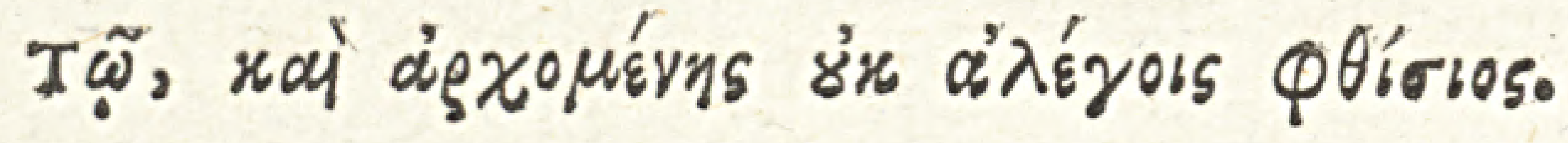


Cherfydrus occifum labio fpirante cadauer

Obuius, haud dulcis meta vigoris erit.

Tutus eris Cæfar terras aditure calentes,

Si Lybicx talos urat arena vix.

Non feret Amphisbæna dolum, fuccique maligni

Ranula, quæ ficci pafcua ruris amat,

Eft facilis ftomacho femper medicina tumenti

Sanahitque cito bronchia ad afthma cadens.

Aut ubi ventriculum circa cum murmure flatus

Fluctuat, \& liquidum furdior unda mouet.

Tormine fi fruo fint inteftina coacta,

Aut pulfu longi fubfiliente coli,

Si totum corpus diffufa bile redundet,

$\mathrm{Si}$, naturali tunc pereunte cute,

ICterus eft æaris, quando odit naufea vitam,

Annuat his feclum luppiter ipfe licet,

Pectora fi fuerint moelto mœrore repleta,

$V t$ fugiant noftras corde tremente domos.

Hydrops fi dirus, pallorque infecerit album

Corpus, mox venis languor aquofus abit.

Sint hebetes oculi, Iplendebunt lumine puro,

Effugit incipiens nil remorata Phtifis. 


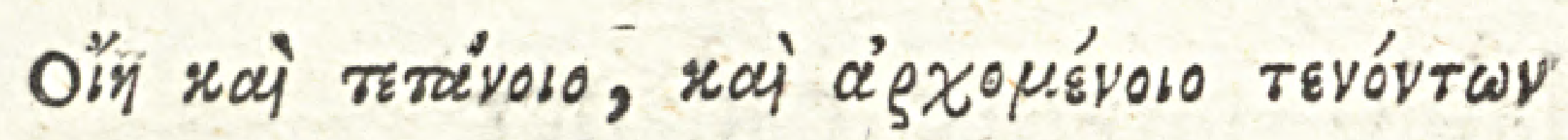

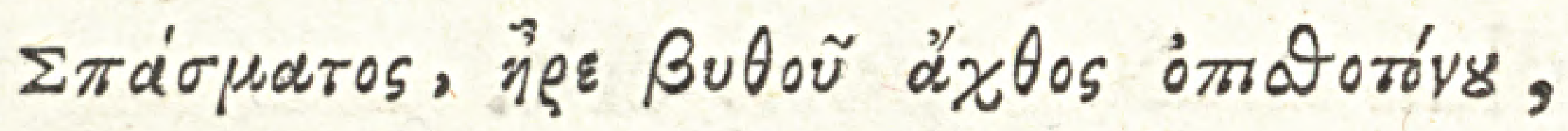

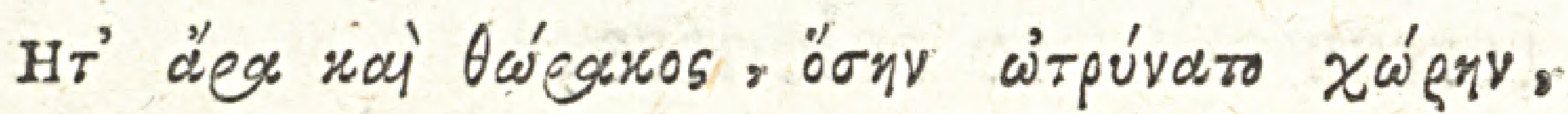

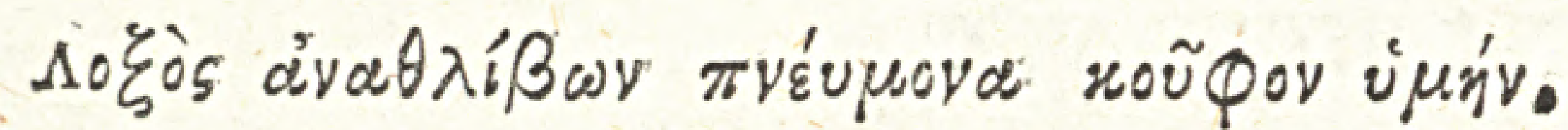

H ö

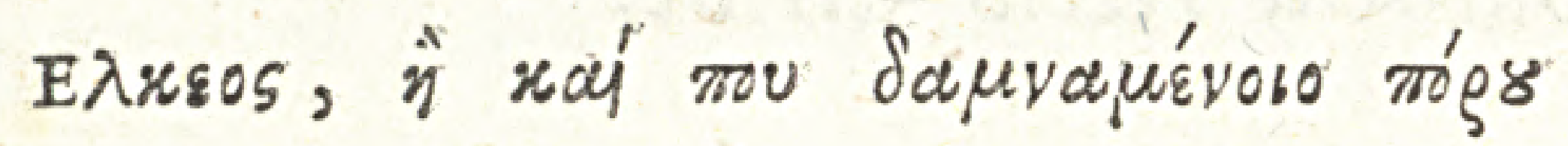

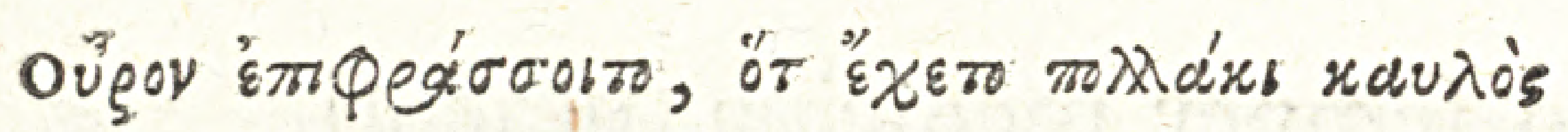

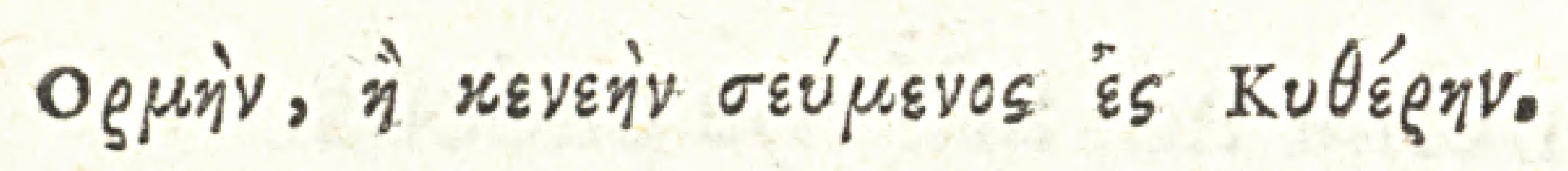

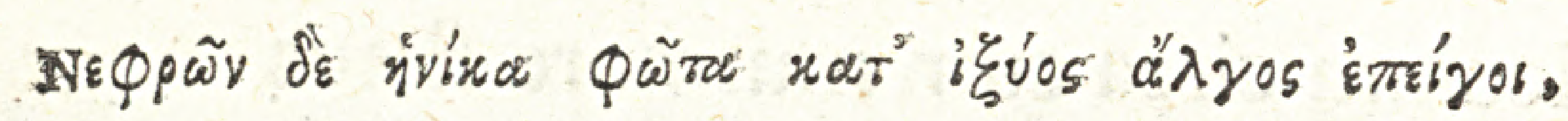

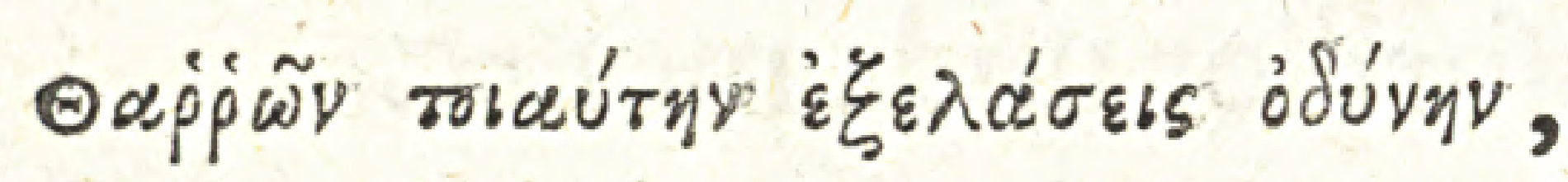

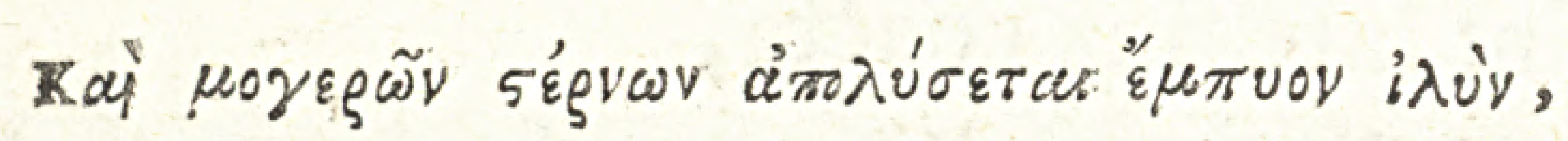

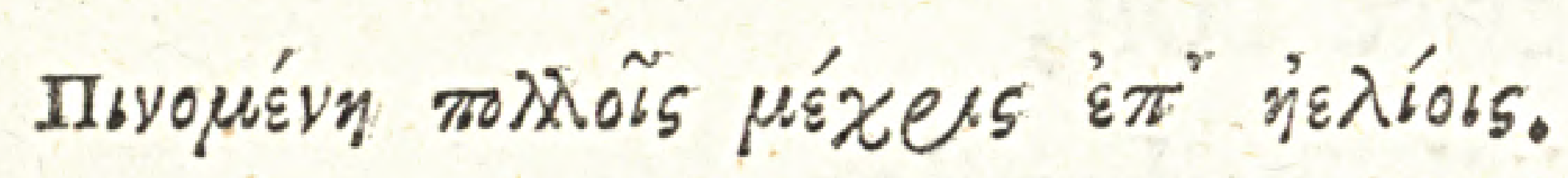

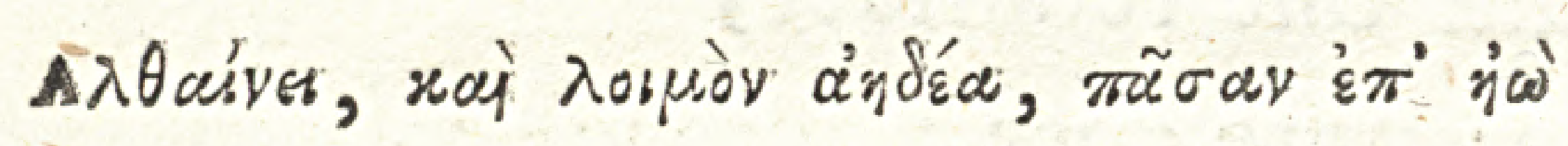

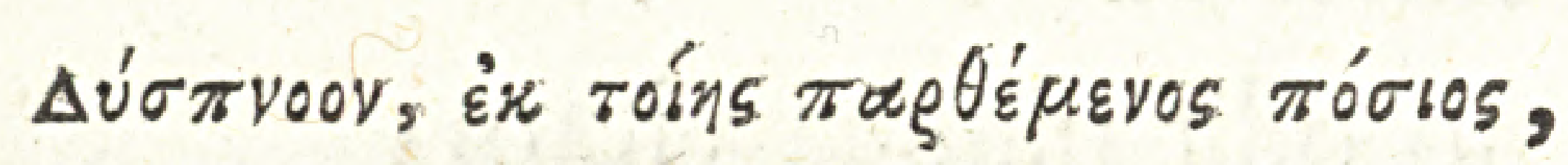

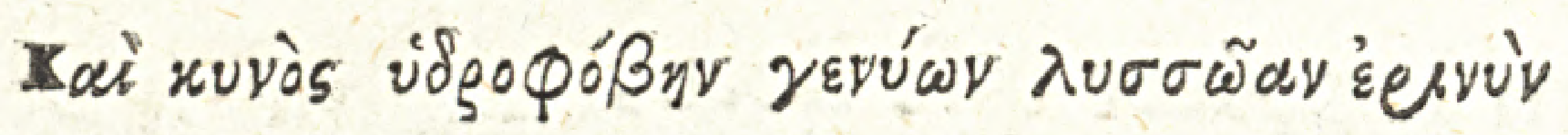

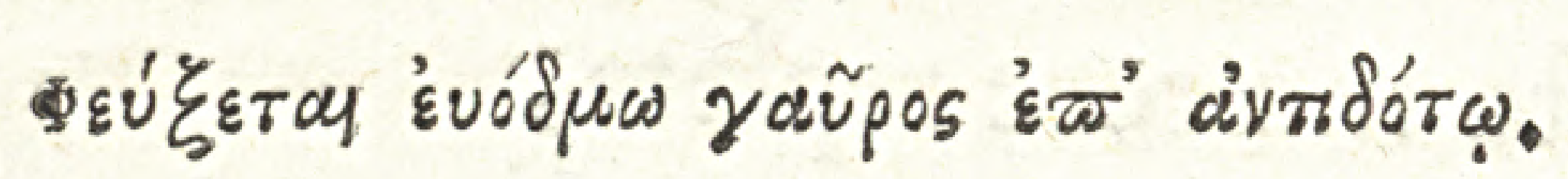

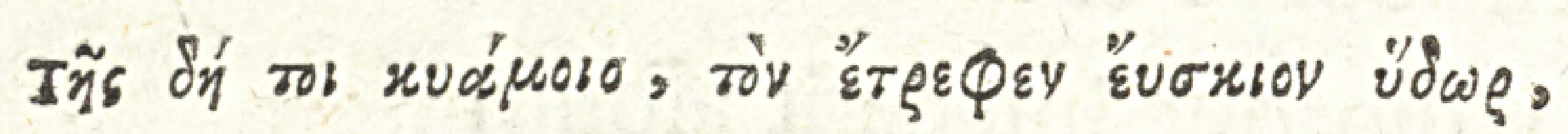

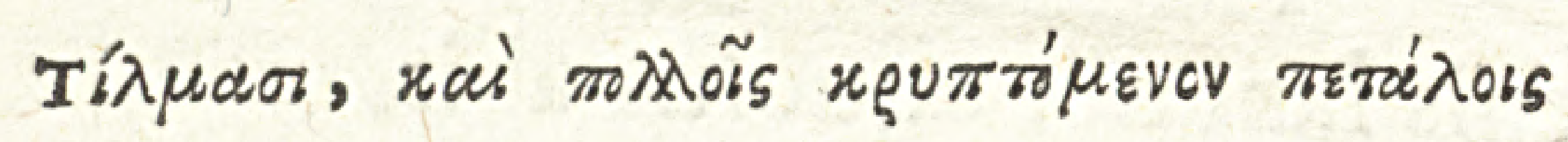

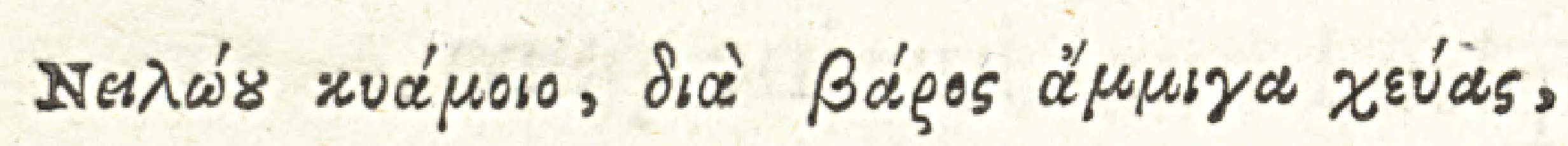

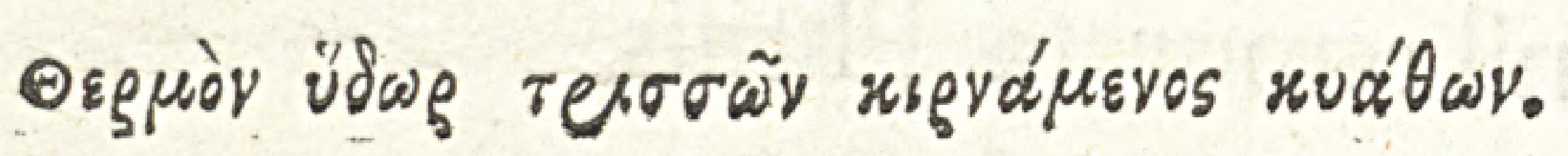


Succumbit Tetanus, maiori tendine motus

Spafmus, Opifthotonos funditus inde perit.

Solatur pectus, quantum fpatii occupat ipfum,

Oblique premitur fpiritus inde leuis.

Horrificum circa veficam lancinet ulcus,

Cuius confenfu iam fuperante porus

Obftruit urinam, tumeant ut vafa Priapi,

Et quafi molimen tentet inane Venus.

Si doleant lumbi et tecti pinguedine renes,

Hoc mifer auxilio macte, valeque tuo.

Pectora difficili mundat faniofa fcreatu,

Potio pro multis ifta diebus erit.

Depellit peftem, fotor quum fpiret in auram

Quotquot eunt illa prædominante, dies.

Qui timor horret aquas rabie mordente, canumque

Vult furor antidoti, gaudeo, odore fugam.

Faba refert pondus, cœno quam nutrit et umbra

Flumen, ubi foliis obruta tota iacet,

Qualem Nilus alit, fi iufto pondere mixtam

Sub tria feruentis pocula condis aqua. 


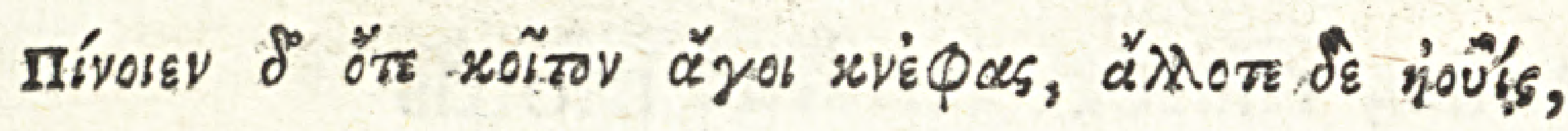

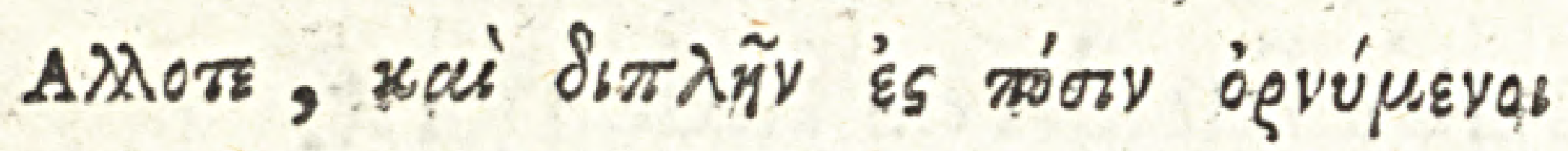

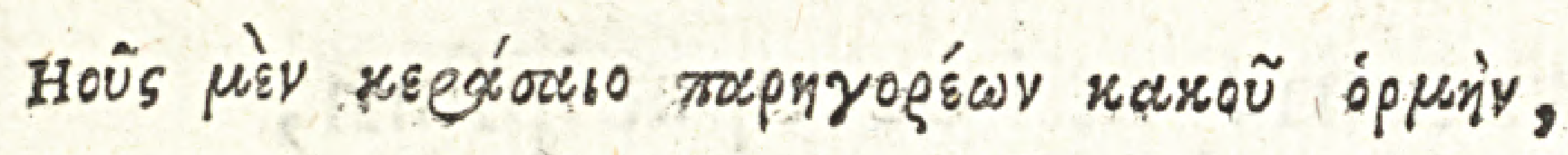

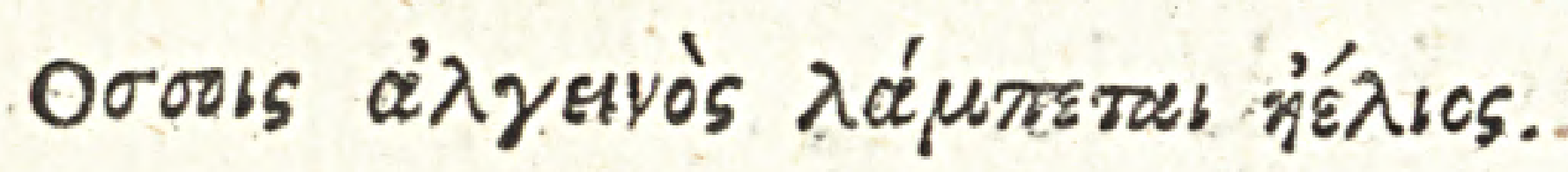

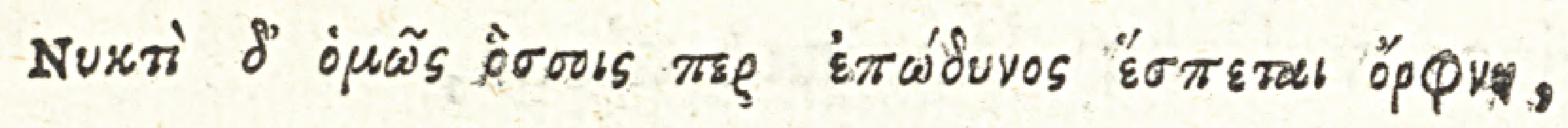

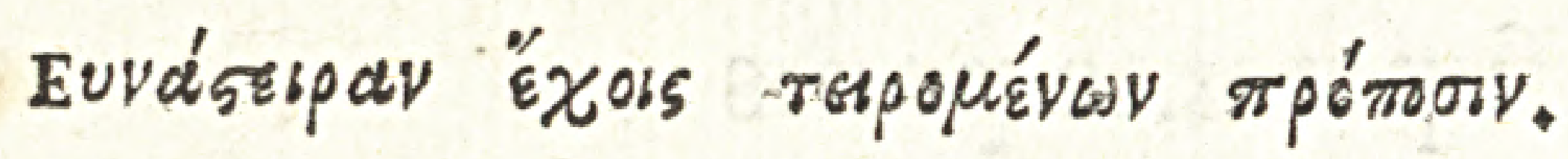

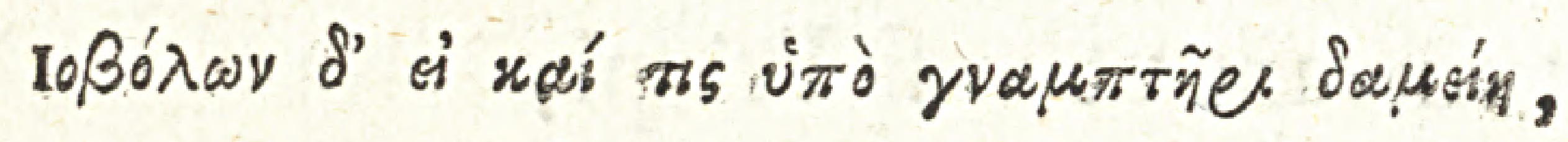

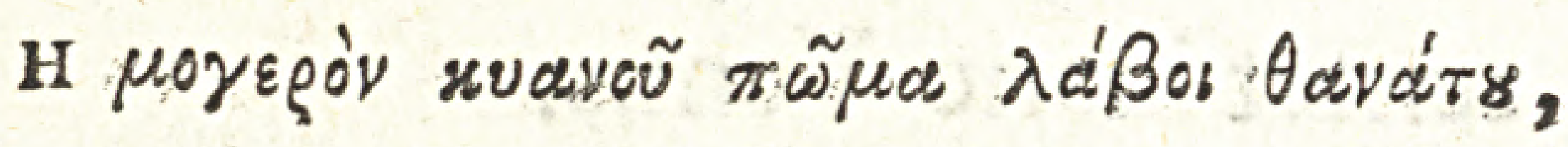

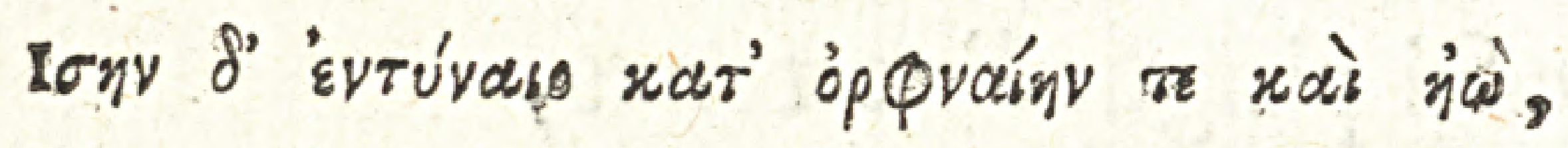

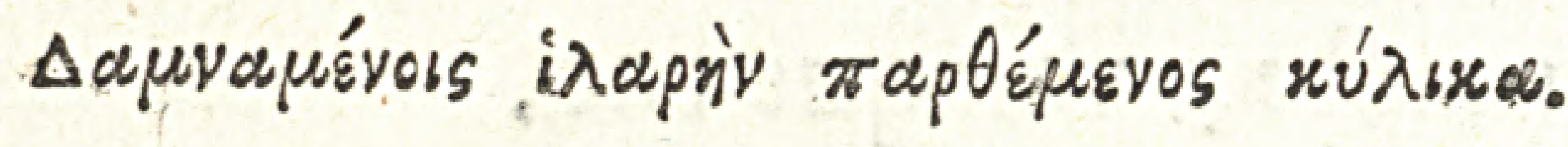

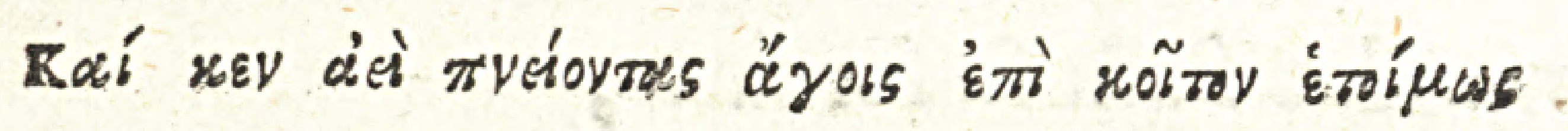

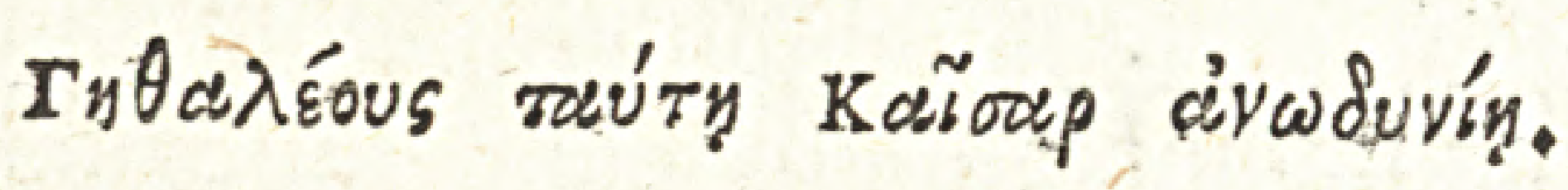

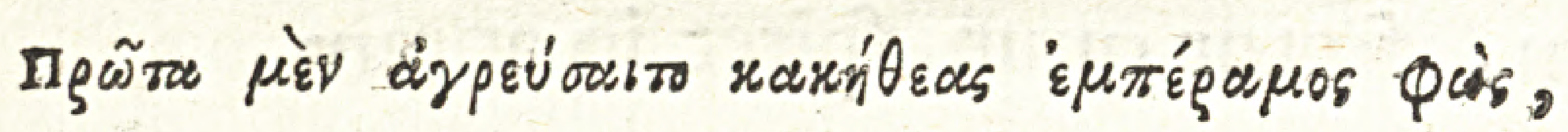

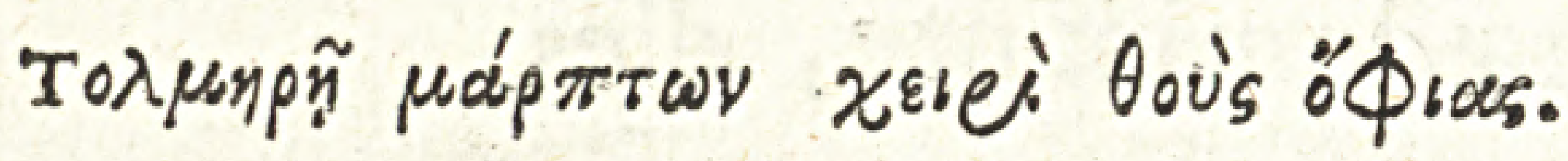

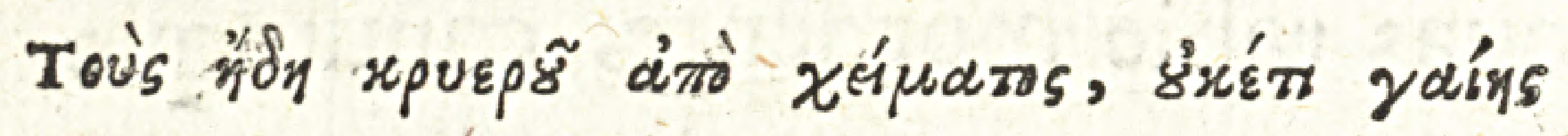

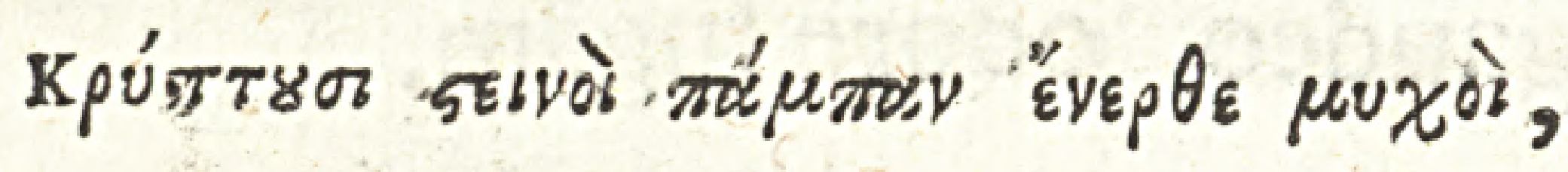

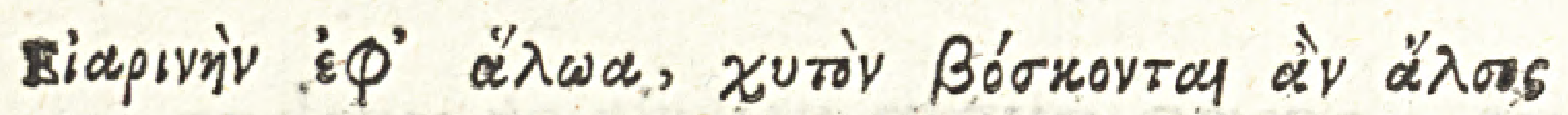

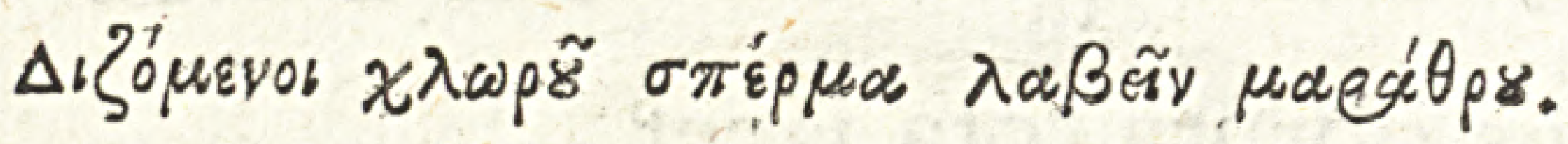

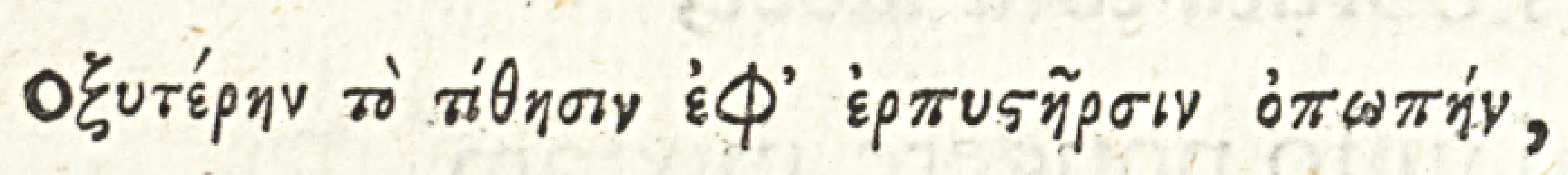

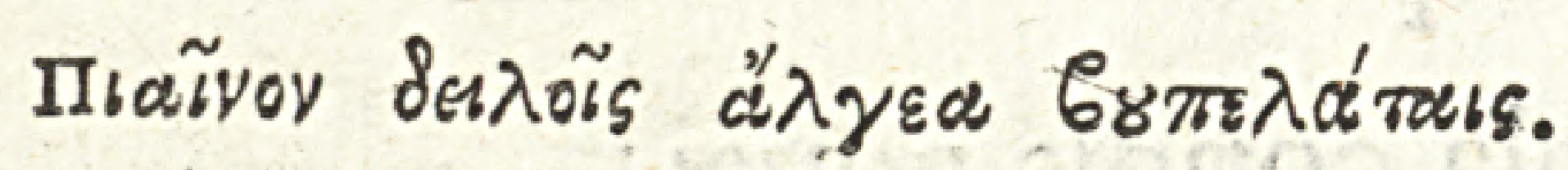

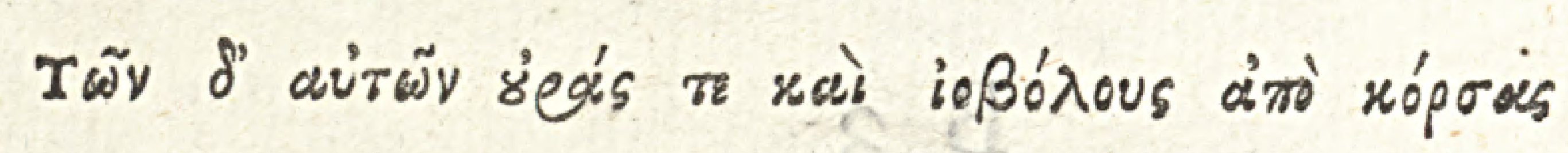

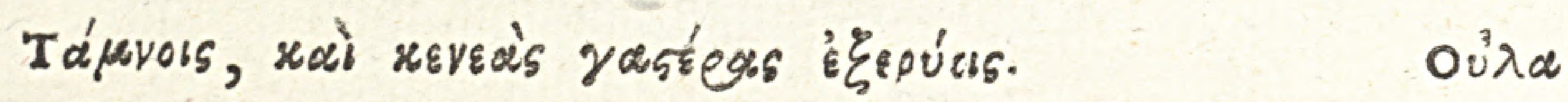


Hanc cape fub nockem, fub folis frpius ortam,

Sapius et duplum fumere cura monet.

Mane tamen femper præbet folamina diris

Morbis, mœefta quibus fulget amœna dies,

Vefpere fub fero pariter conducit et illis,

Triftia fipe quibus tempora noctis erunt.

Siue venenati ferpentis vulnera læedant,

Seu fint obfcurx pocula fumta necis,

Hefperus et Titan tunc fpectent dofin eandem:

Sumitur ingenti profperitate calix.

Semper anhelanti fomnum, requiemque paratam

Antidotus, Cæfar, fuaue leuamen, habet.

Ergo malas angues venator de arte peritus

Audaci tanget, corripietque manu.

Frigora polt hyemis feui non amplius antrist

Anguftis, terræ fub loculisque latent.

Area tunc vernans, nemorofaque pafcua ducune

In lucem; marathri femen amantque virens.

Acrius ut cernat, viresfunt illius, anguis,

Pinguefcit dolor hinc mœite bubulce tuus.

Demete protenfam caudamque caputque venenis

Infectum: tum quæ vifcera venter habet. 


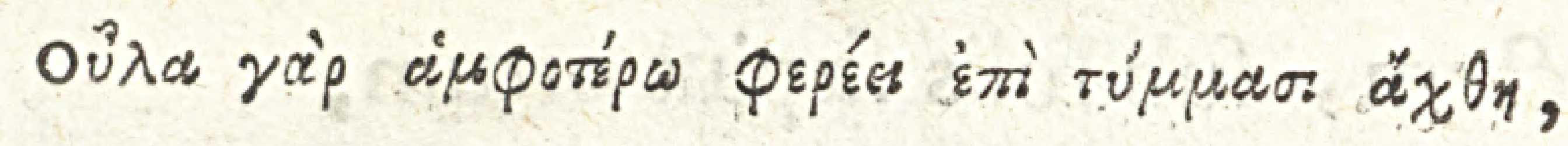

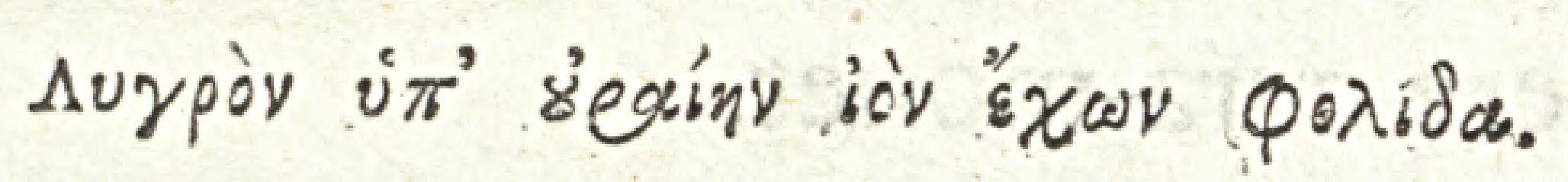

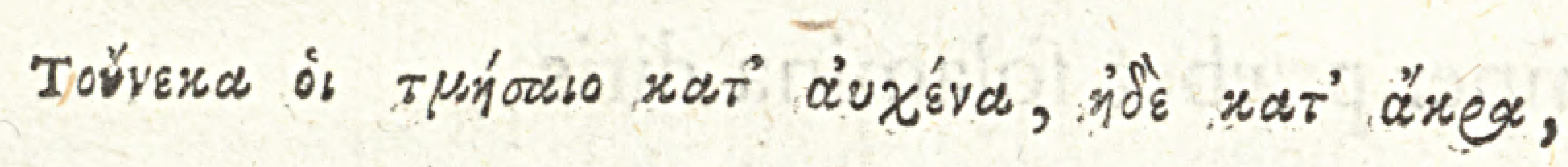

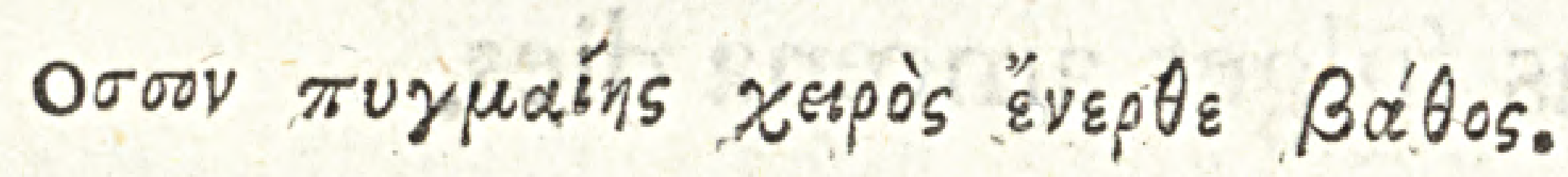

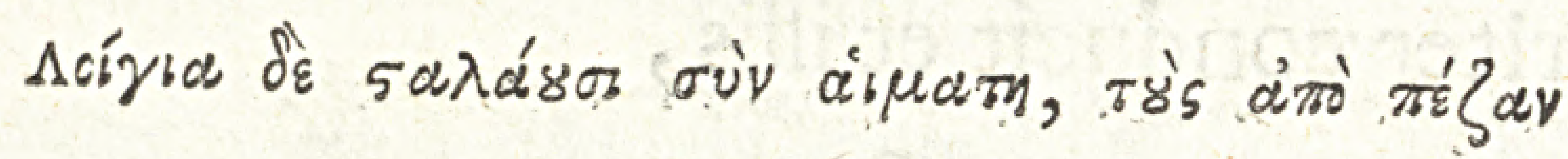

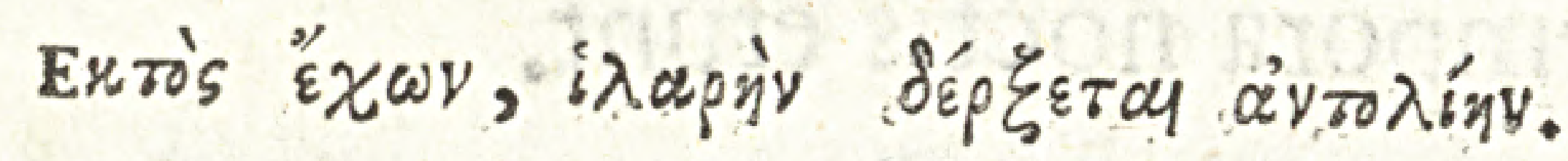

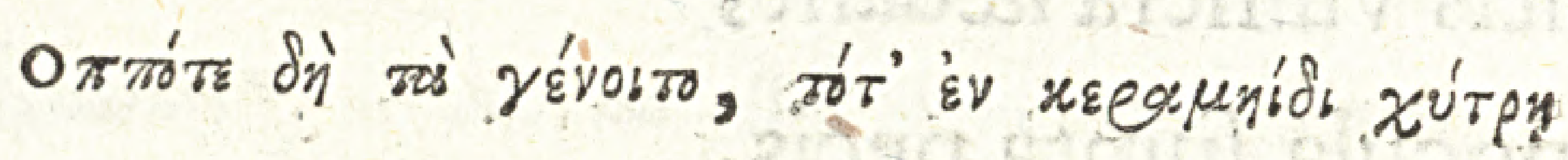

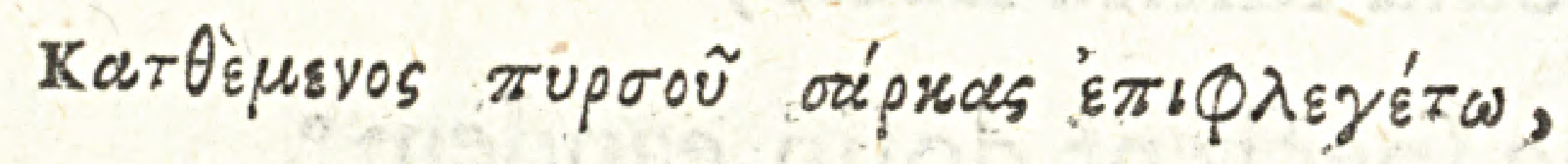

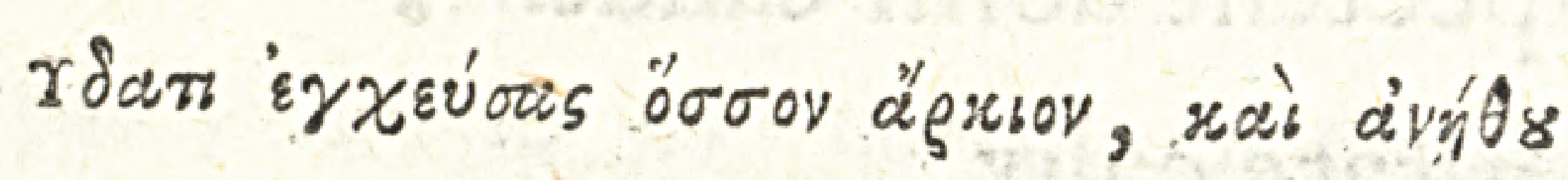

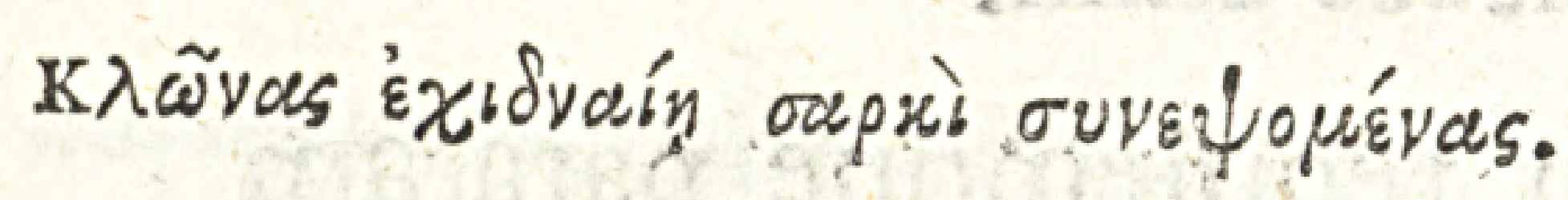

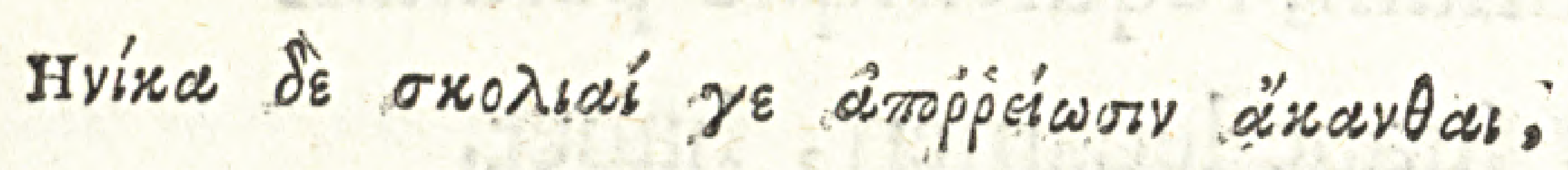

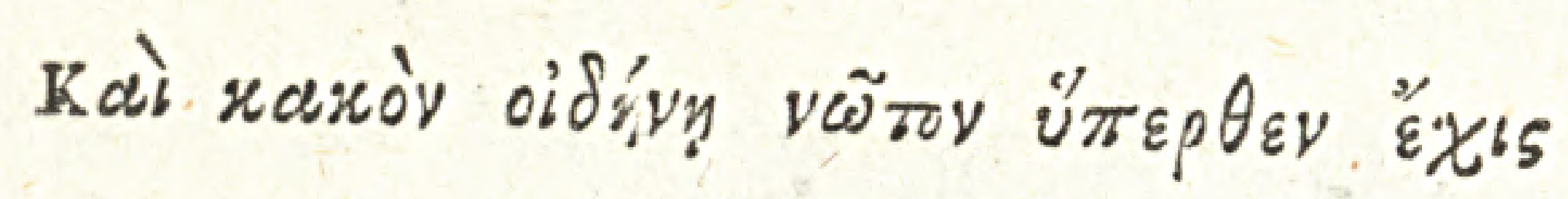

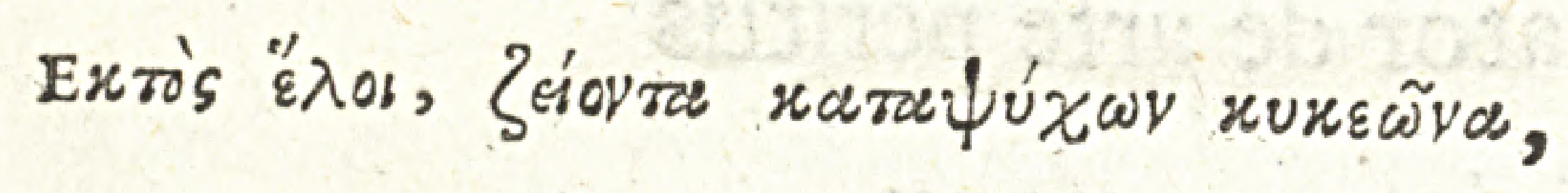

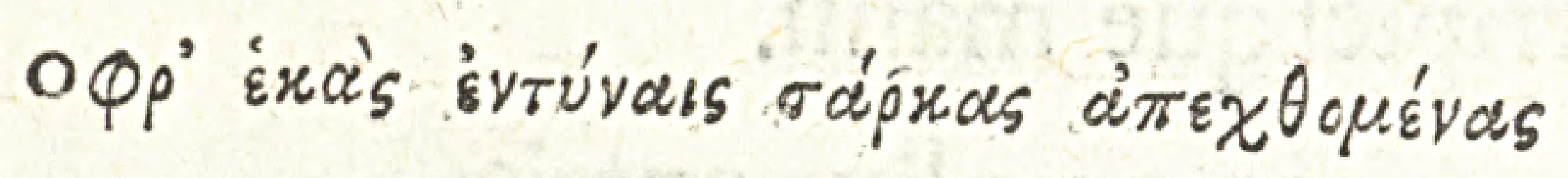

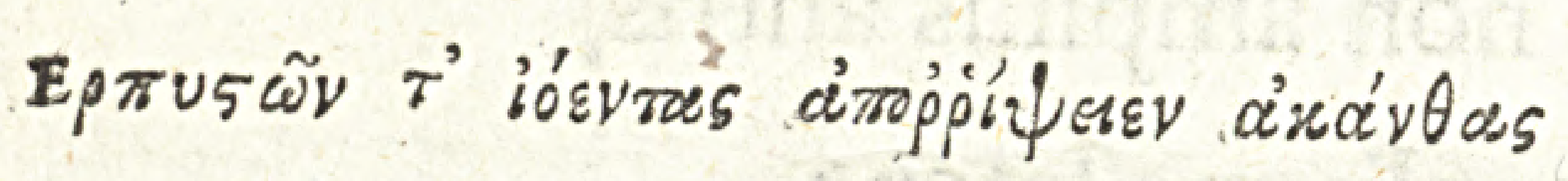

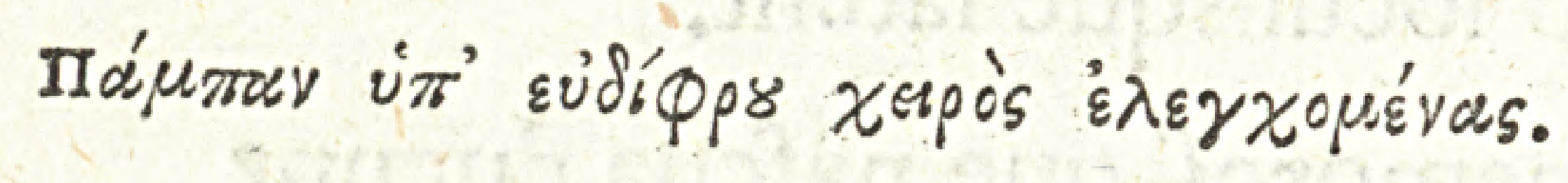

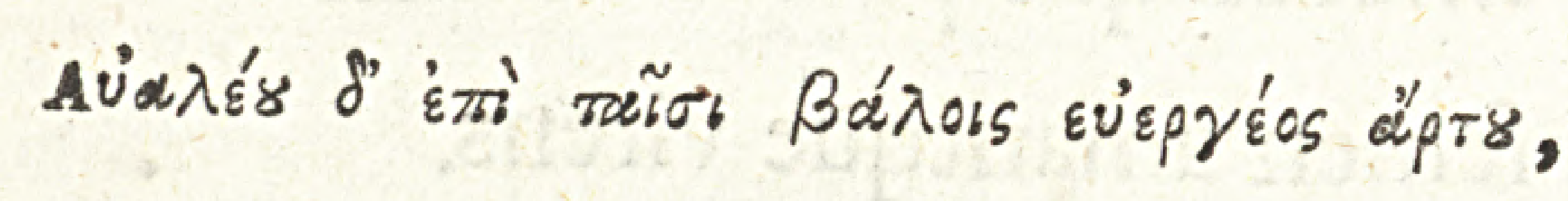
Oroov repoúvas oxipxd, dúvarto tpoxois

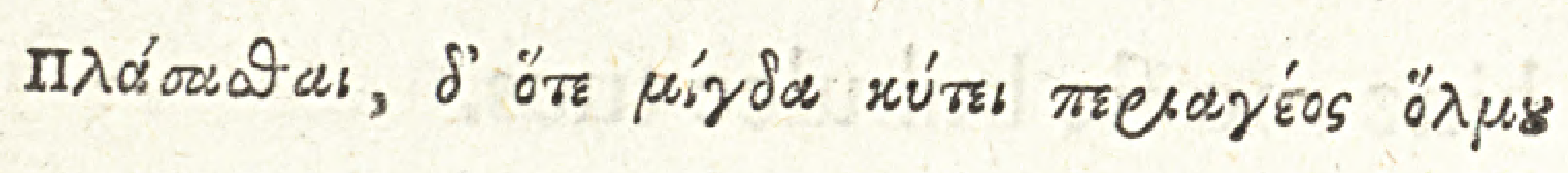

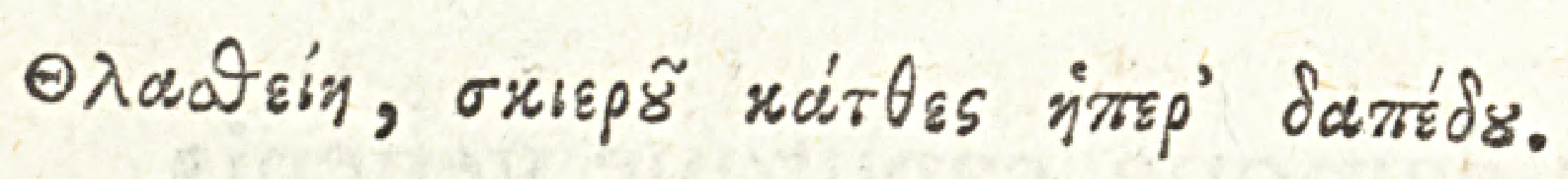


Scilicet extremo fert vipera vulnus utroque

Peflima fub fquamis toxica cauda trahit.

Hinc tantum caudær refeca, cervicis et atræ;

Quantum Pygmæi continet apta manus.

Noxia ftillabunt cum fanguine, qui cauet ifta

Plantis, fol ifti latior ortus erit.

Hoc poftquam factum eft, figulina prorfus in olla

Exuuias rutilo verberet igne calor.

Addis aqux quantum tibi fufficit, vt fit Anethi

Pars cum viperea carne coquenda fimul.

Separet intortas lymphæ vis ignea fpinas,

Tergora quum tumeant tam metuenda feræ.

Extrahe tunc inter fefe feruentia pulpæ

Fruftula, quæ remoues difflet ut aura procul.

Reptilium vero fufpectas fubtrahe fininas,

Arguet has fenfu palma perita fuo.

Siccatum et piftum tandem fimul adiice panem,

Quantum vult fluidum hoc, ut rotulam inde premas.

Hoc mixtum tundas penitus mortario in amplo,

Ac fuper umbrofo cuncta repone folo. 


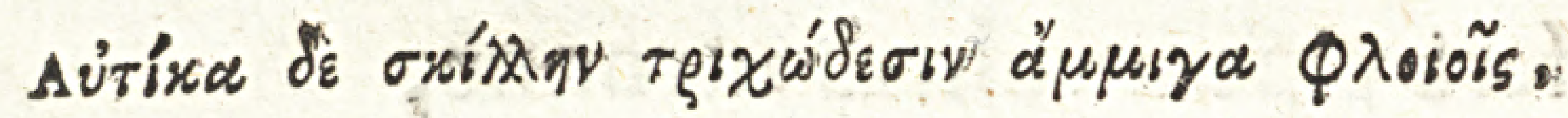

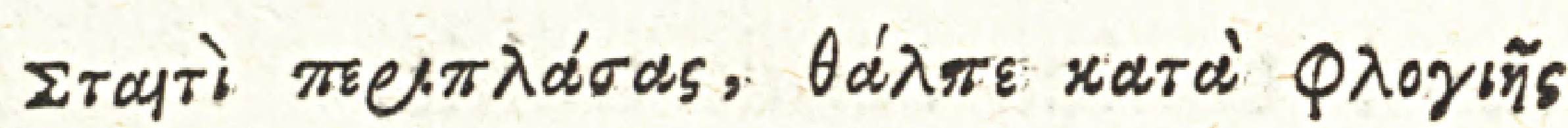

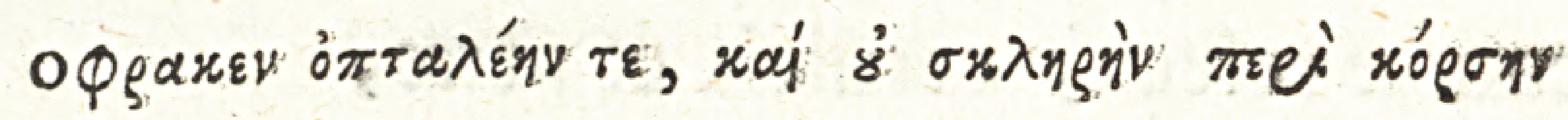

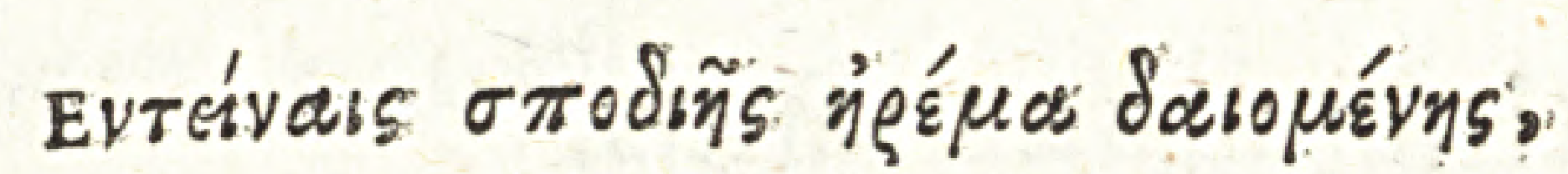

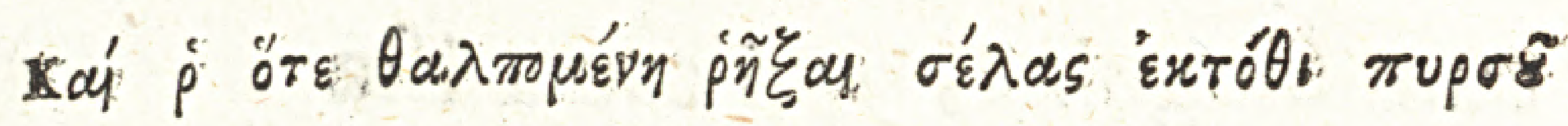

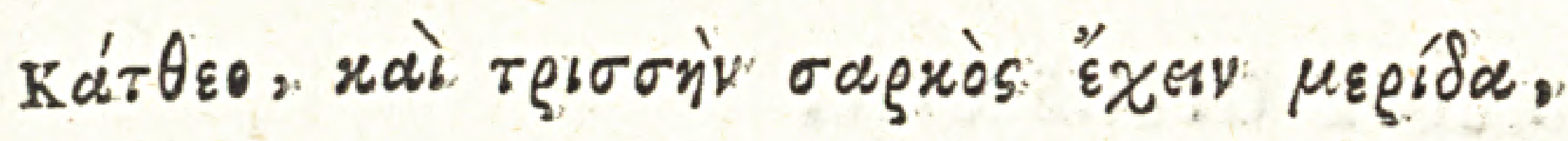

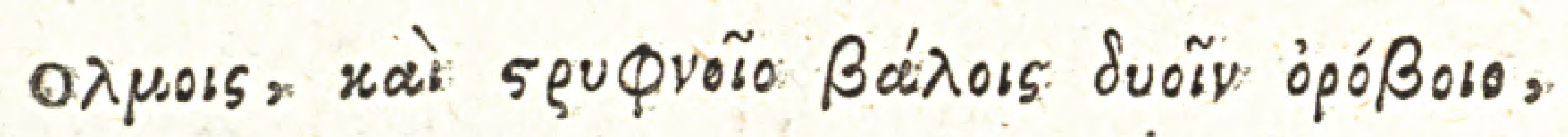

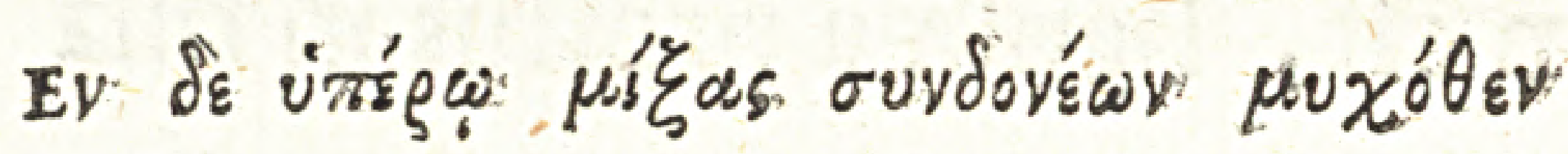

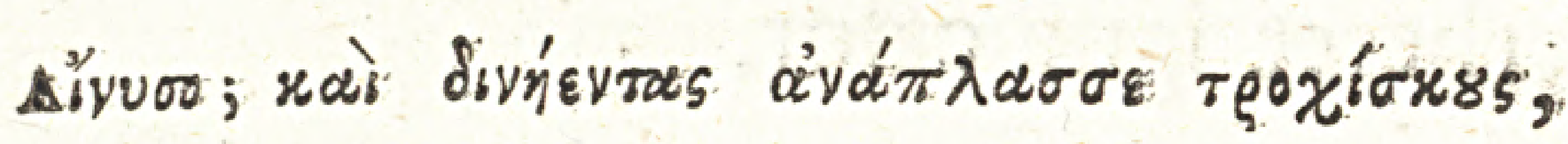

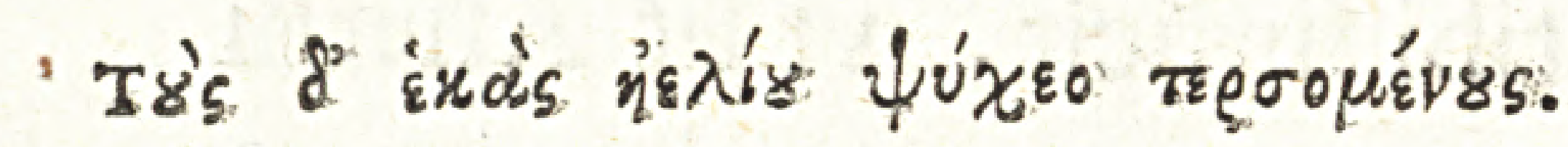

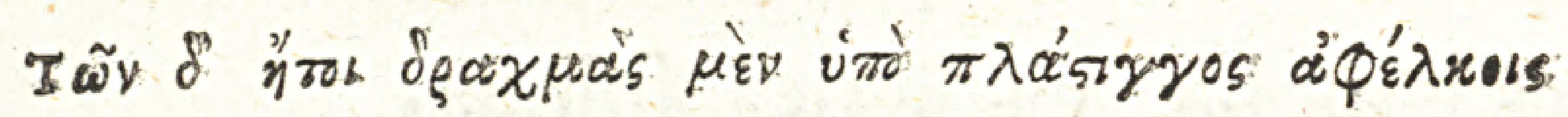

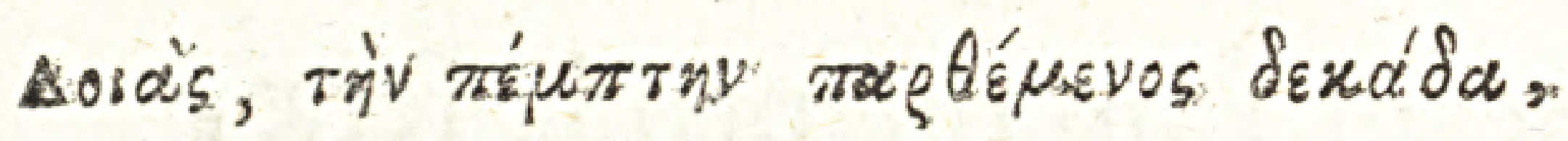

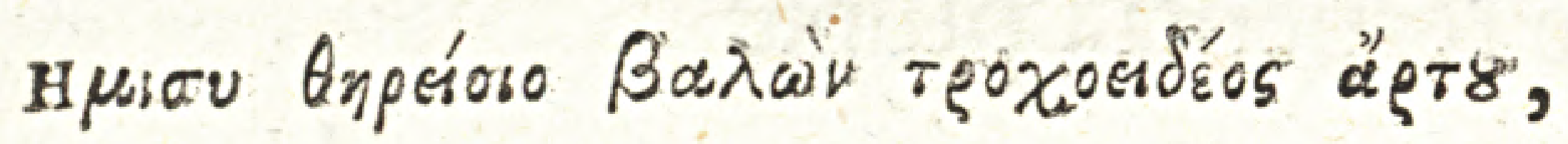

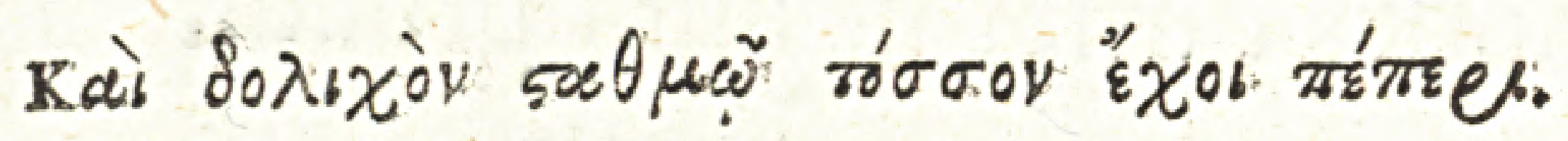

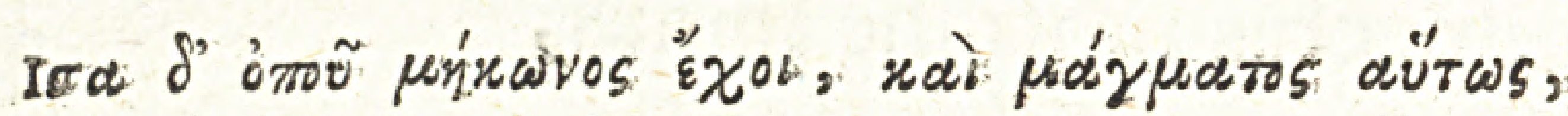

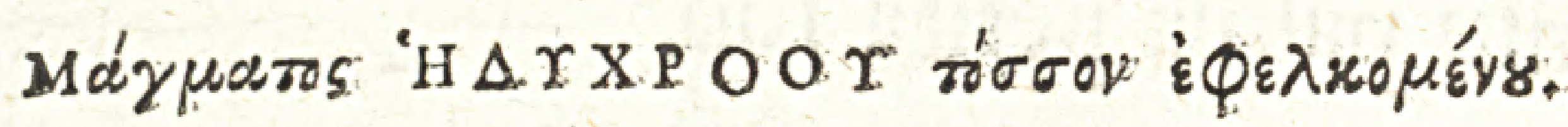

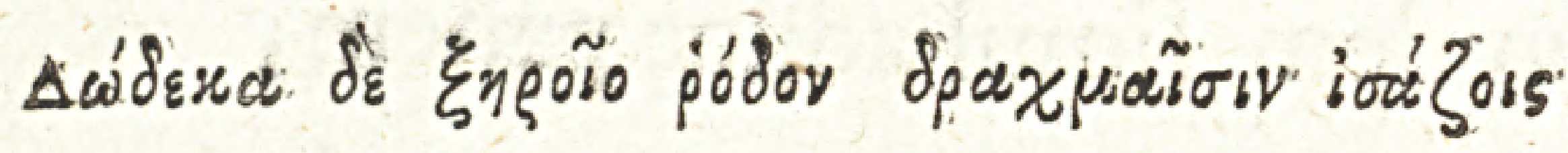

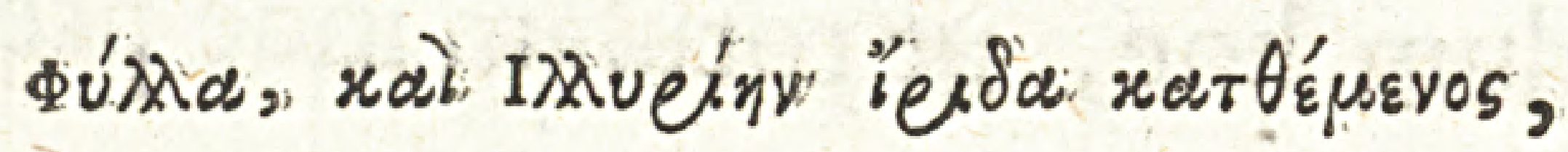

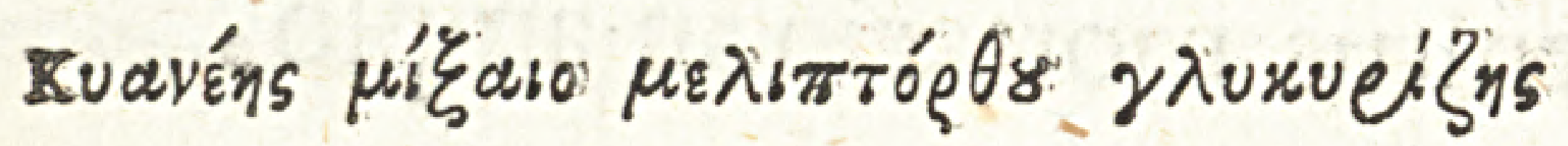

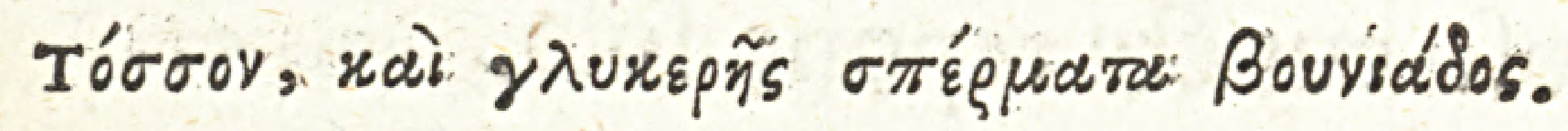

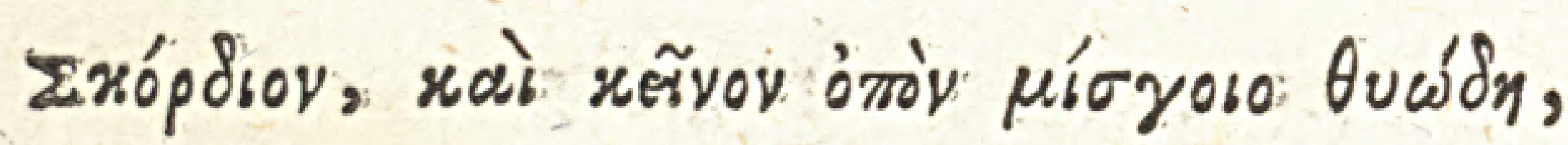

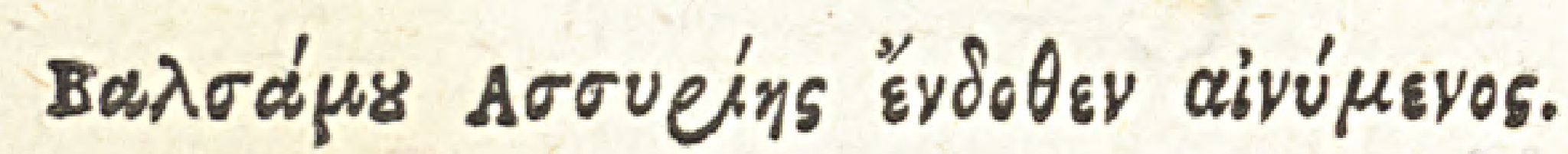


Mox autem Squillam villofo cortice tectam Triticea maffa mixta fit, adde focis,

Donec inaffata eft, nec circum culmina dura,

Sub cineris cumulo fit retinenda fui.

Difiliet calefacta, dein tamen exul ab igne

Nudetur, triplex portio carnis erit.

lunge duas Orobi partes radicis amaræ,

Piftillo moto ferrea vafa fonent.

Perfice, contortos ac hinc tibi finge trochifcos,

In multo hos ficca frigore fole procul.

Illorum geminæ lancis fint pondera drachmæ,

- His tamen impofitis quinta fit apta decas.

Adde trochifcati, cui mixta eft vipera, panis

Dimidium, longum dimidioque Piper.

Sint Opii partes et magmatis huius eædem,

Magmatis, egregius cui folet effe color.

Porro Rofæ ficcæ folium, bis fex cape drachmas.

Iridis illyricx par ita pondus eat.

Mellifluus datur inde tuus Liquiritia guftus,

Tantum de dulci femine, Nape, tuo.

Scordion, atque illum fuccum mifabis amønum

Balfami, ab affyrio littore nempe datum. 


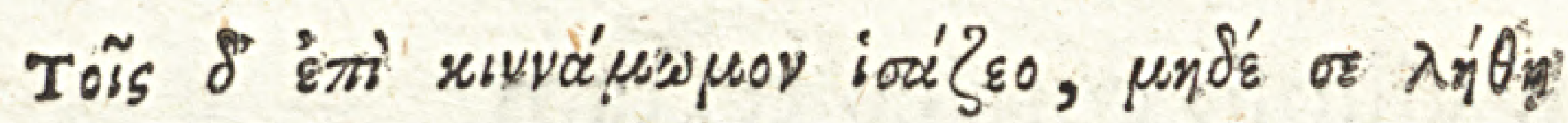

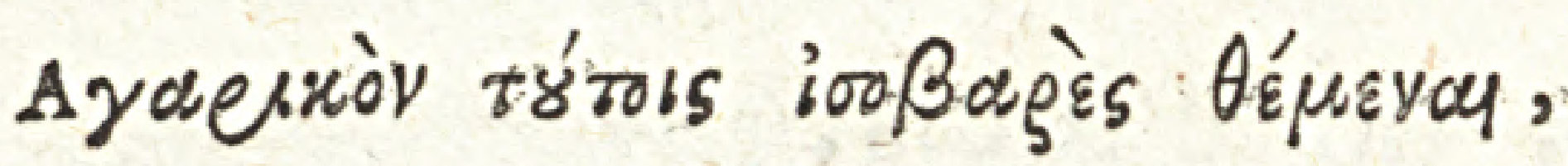

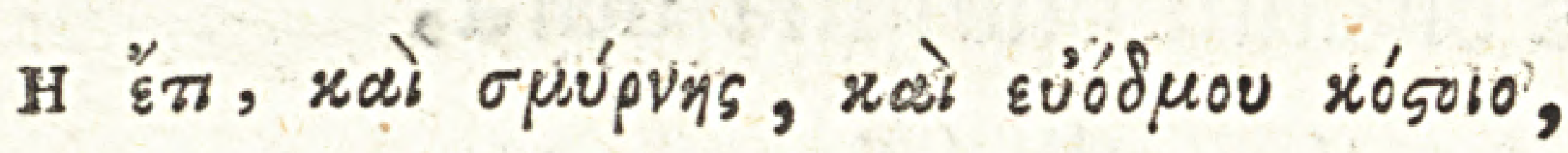

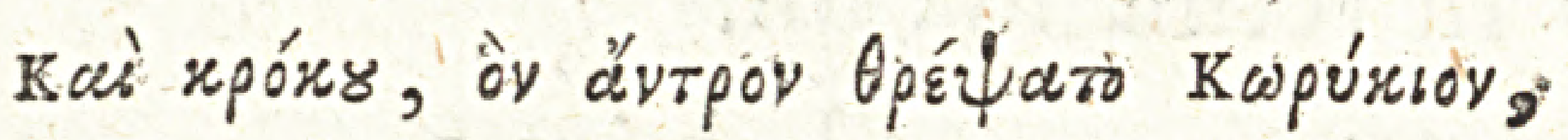

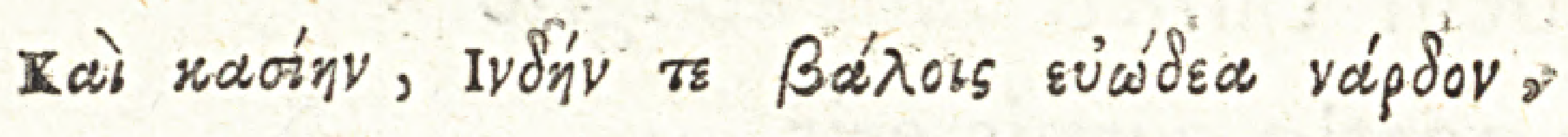

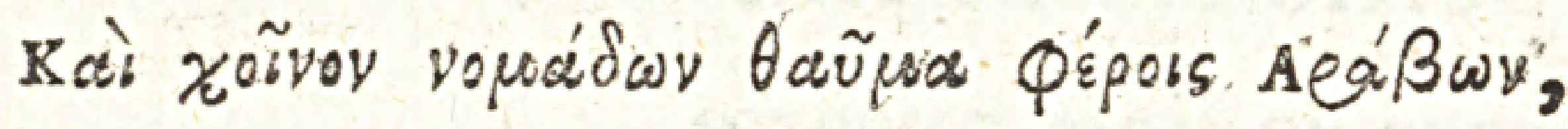

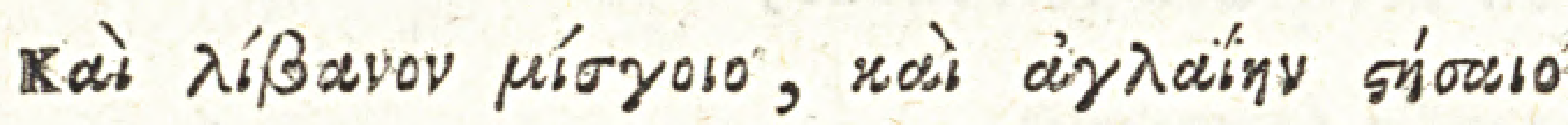

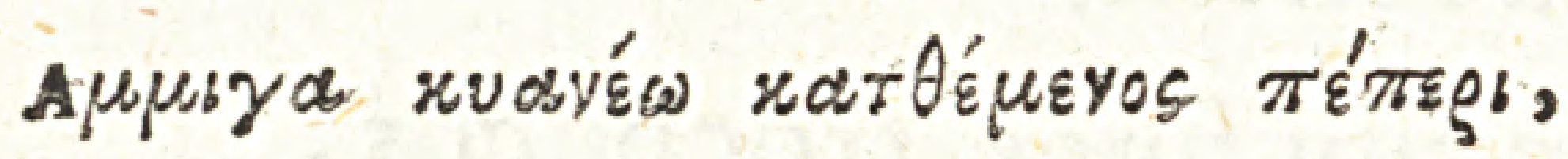

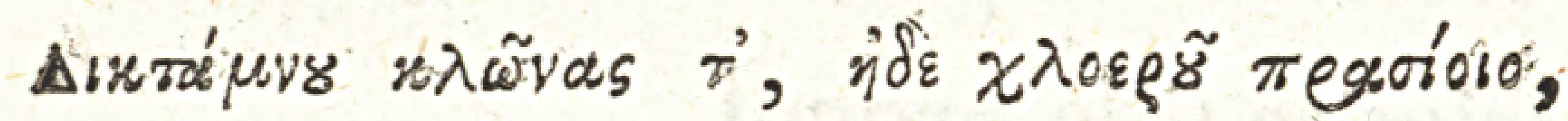

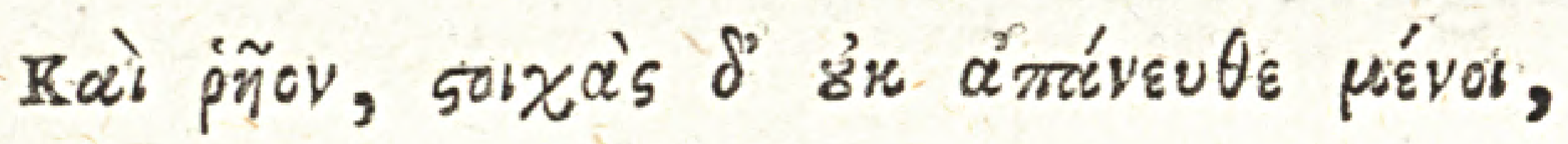

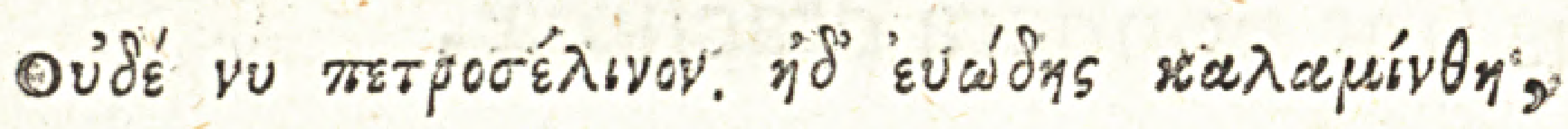

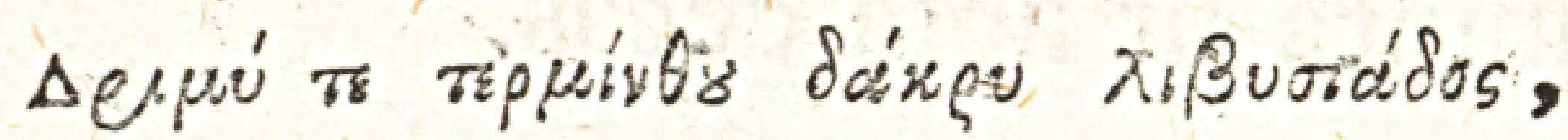

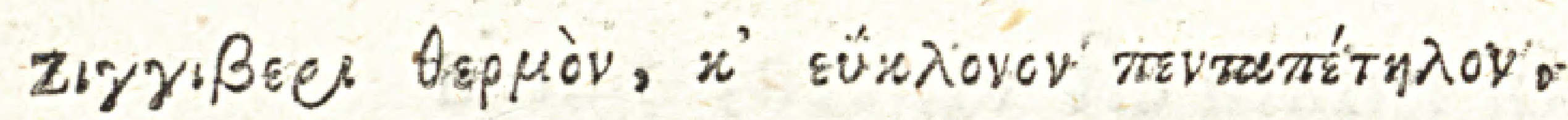

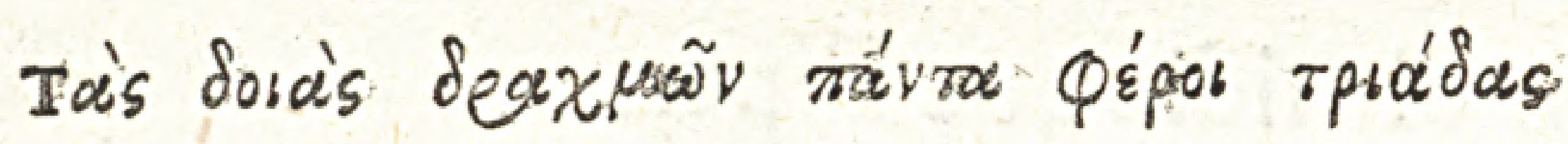

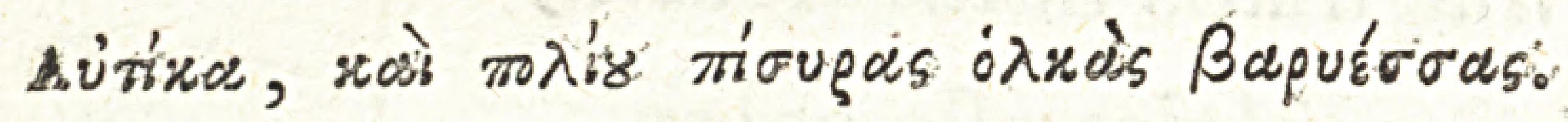

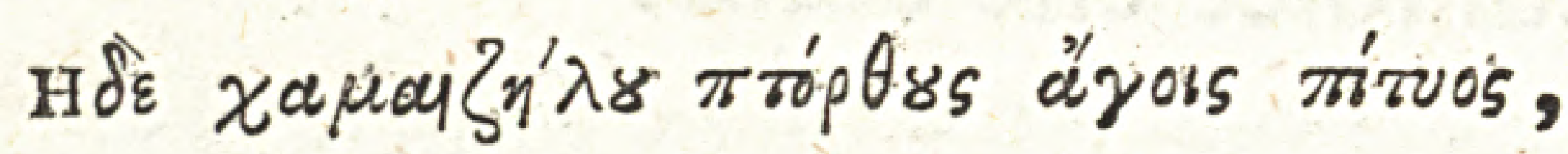

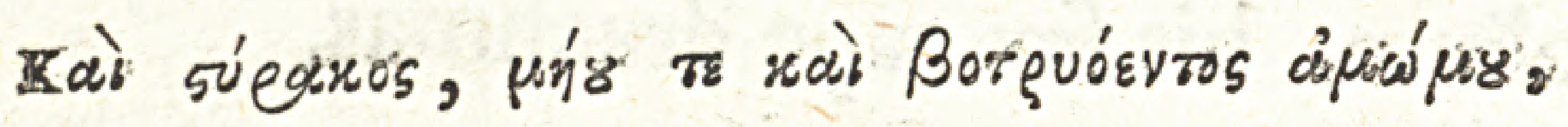

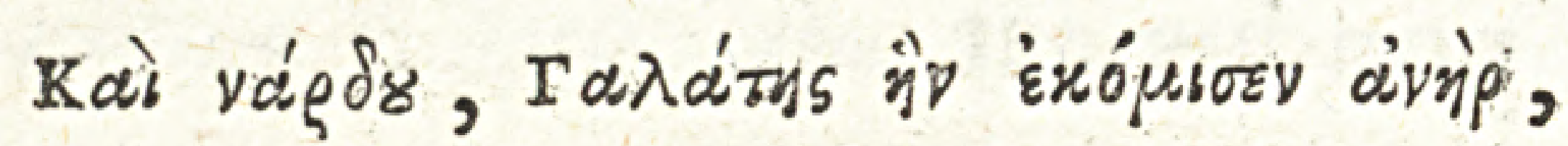

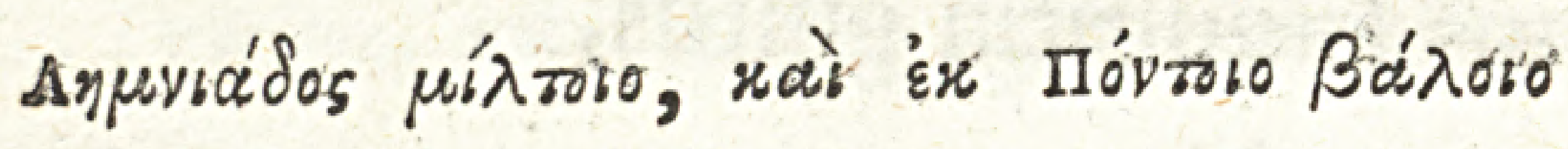

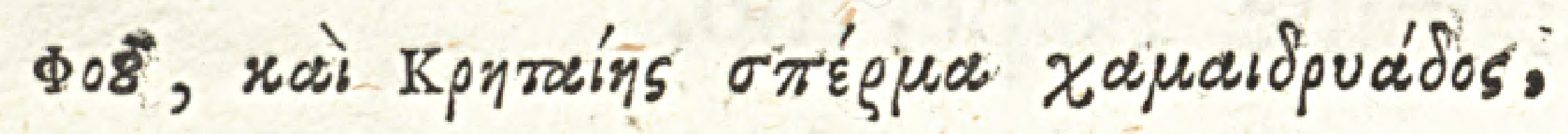

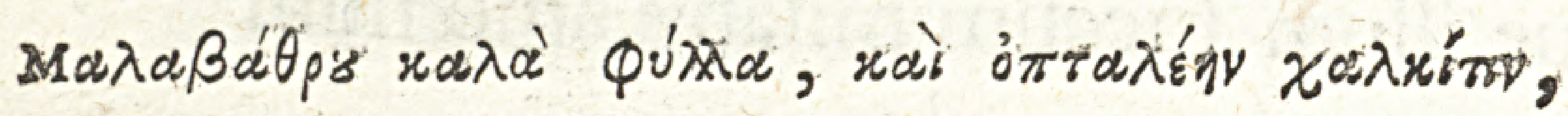

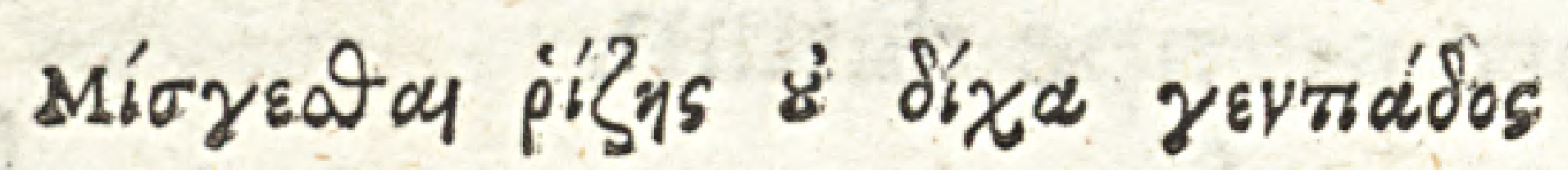


Cinnama prædictis condas æqualia rebus.

Agarico pondus non fuperante tamen.

Infuper adircies Myrrham, Coltumque fragrantem,

Corycio ex antro quem petimusque Crocum.

Et Caliam, nec non Indam cognomine Nardum,

Ac Arabum Schoenum, quod decus effe putant.

Splendida munificis huc transfer thura Sabæis,

Ora fimul mordens nigrius adde Piper.

Dictamnus frondens, viridelcens Marrubiumque,

Rheon, ct huic rurfus proxima Stochas eat.

Petrofelina dabis, quid olens Calaminthe retardet?

Cum lacrumis lybicus qui Therebinthus adeft?

Zingiber exurens, petali tirps nomine quinti,

Pars ut fex drachmas fingula claflis amet.

Quattuor in drachmis Polium fuccedit, et auget

Qux gaudet terræx mairgine Pinus, opus.

lamque corymbifero ityraci fe iungit Amomum,

Nardo Celtarum Meon adeffe cupit.

Lemniacum minium, Phu radix accola Ponti,

Atque Chamrdryados fernen habete locum.

Fœuniculi folio Chalcitis iungito calcem,

Quam Rex radicem, Gentius ille dedit. 


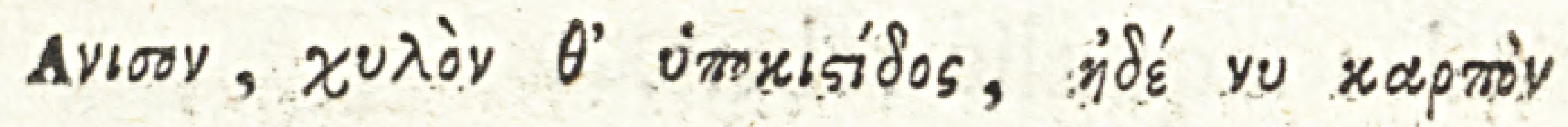

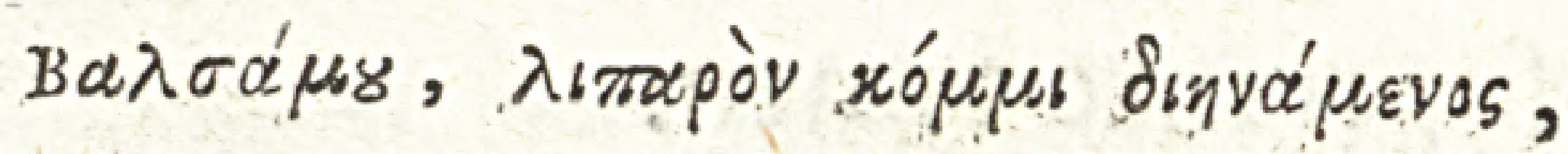

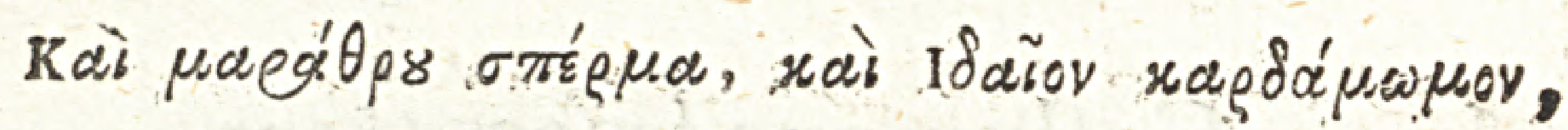

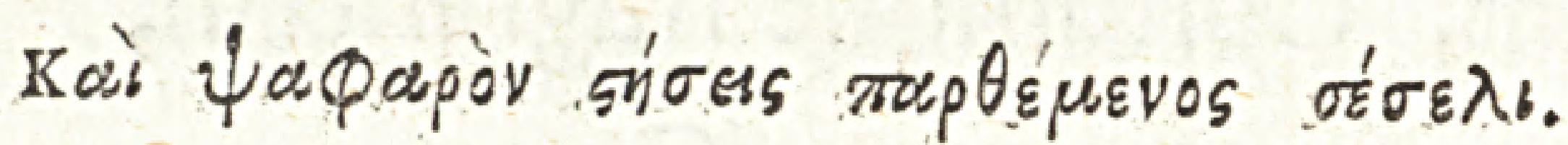

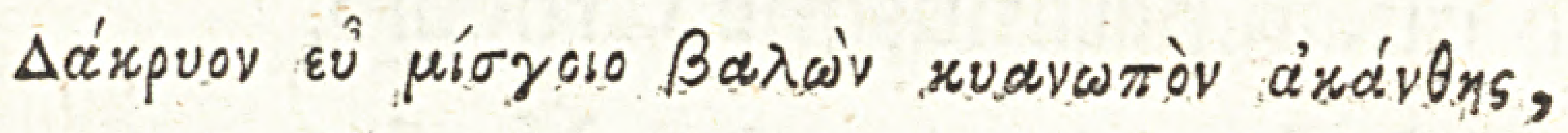

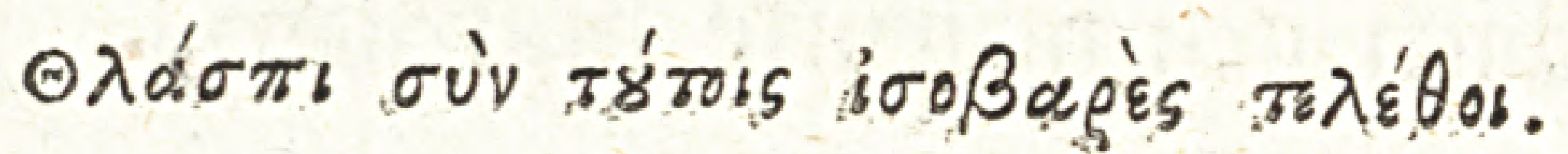

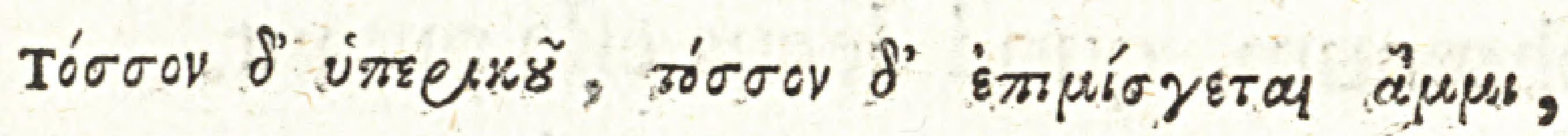

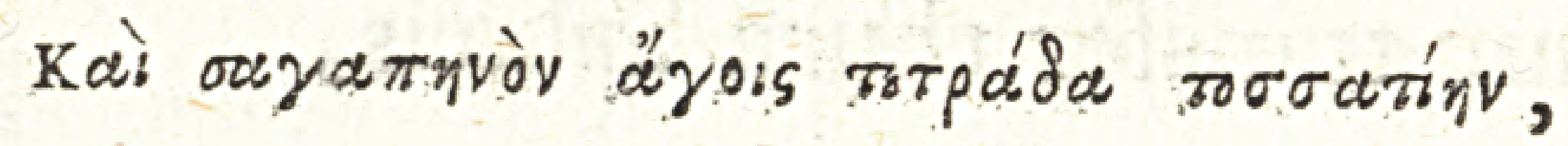

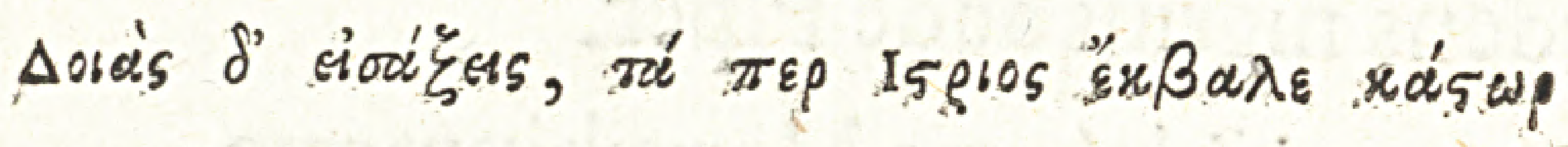

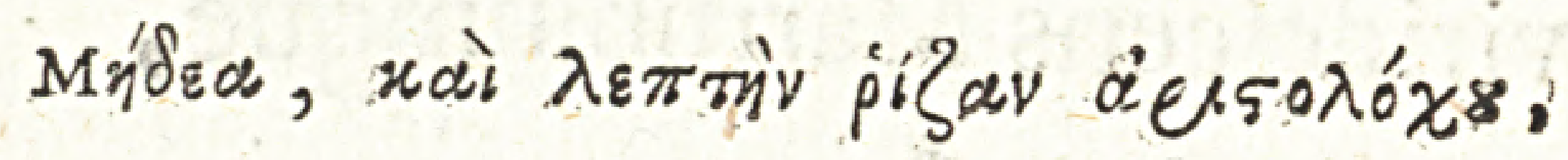

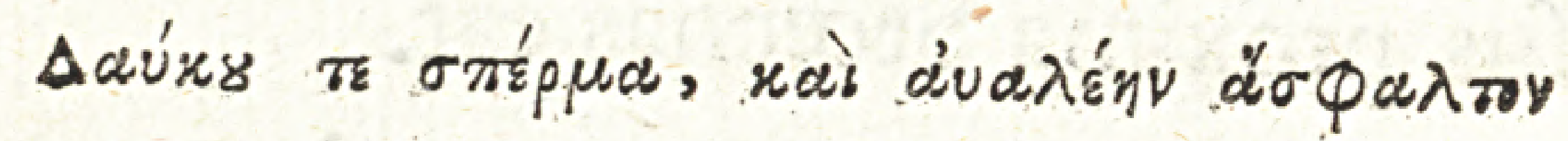

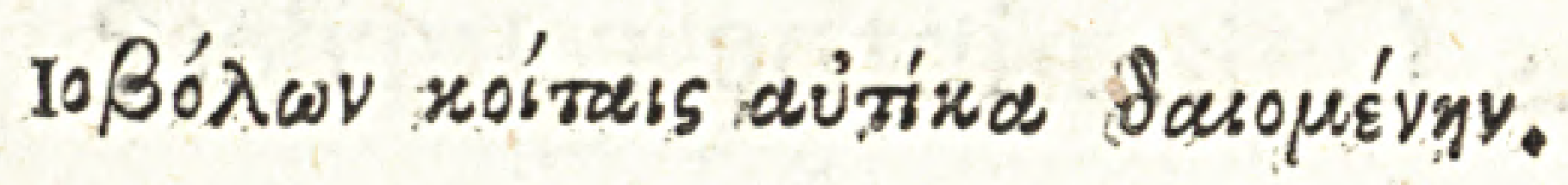

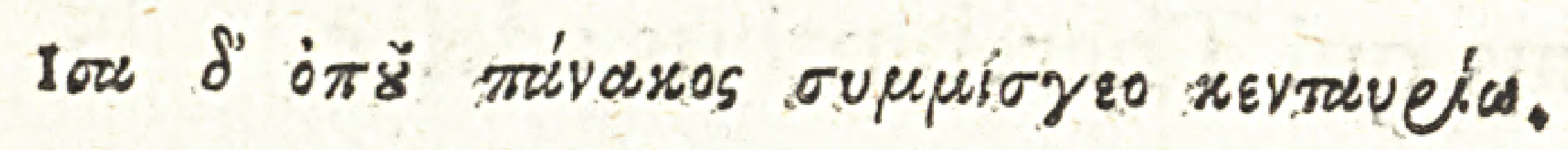

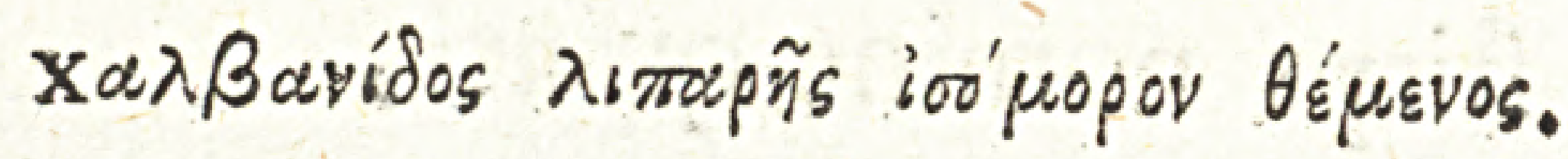

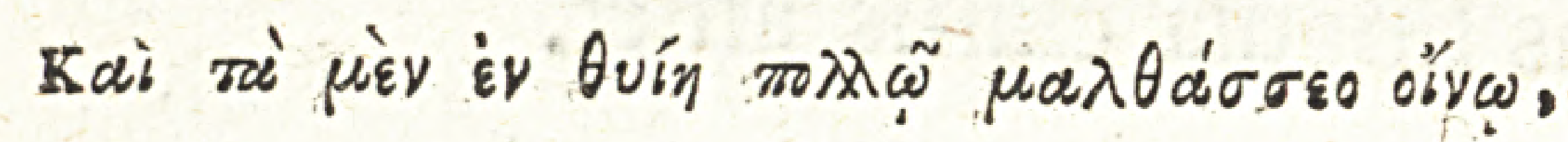

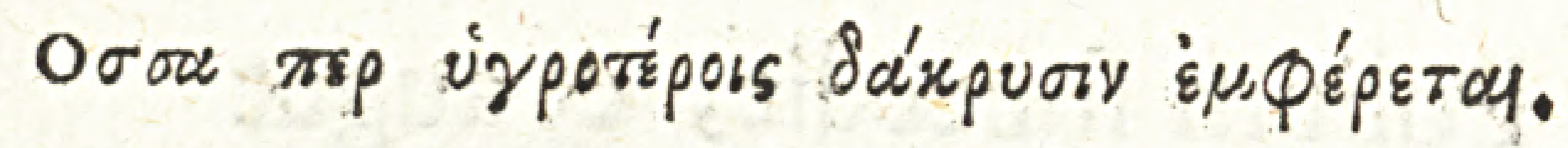

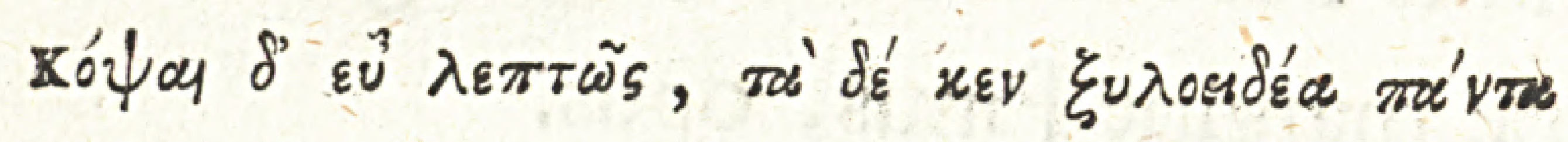

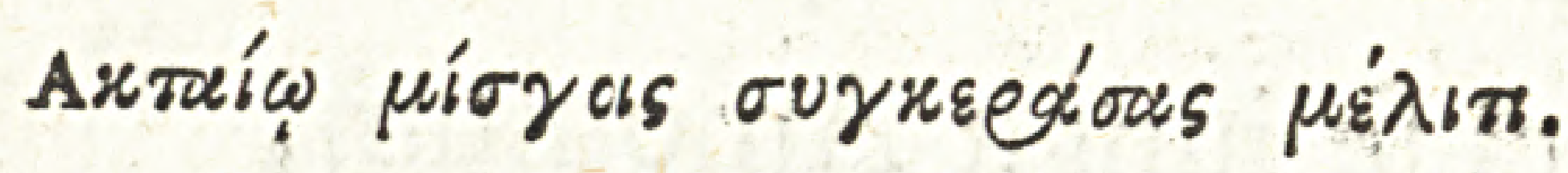

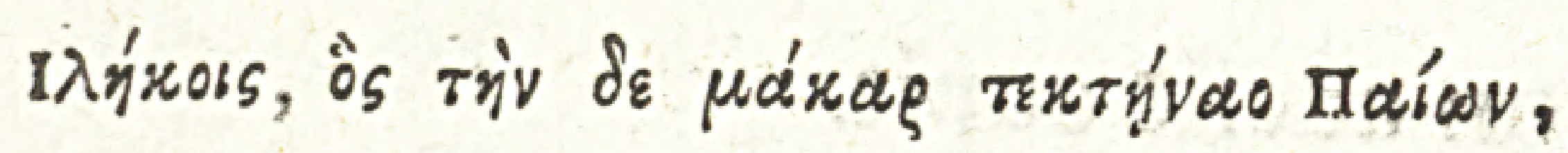

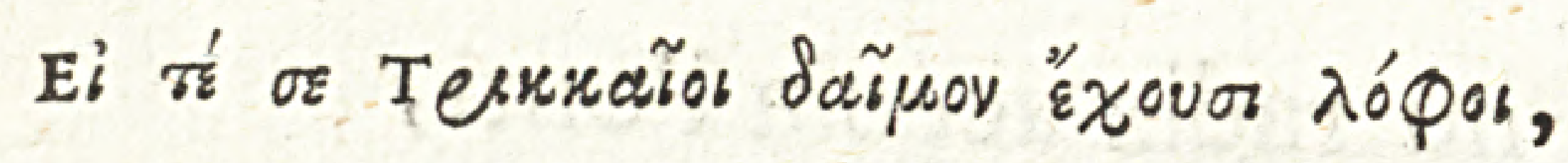

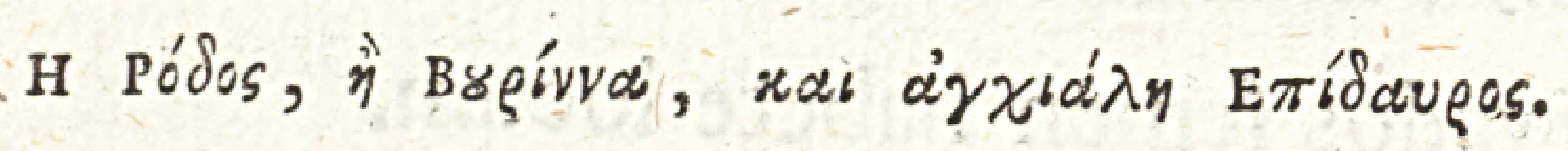

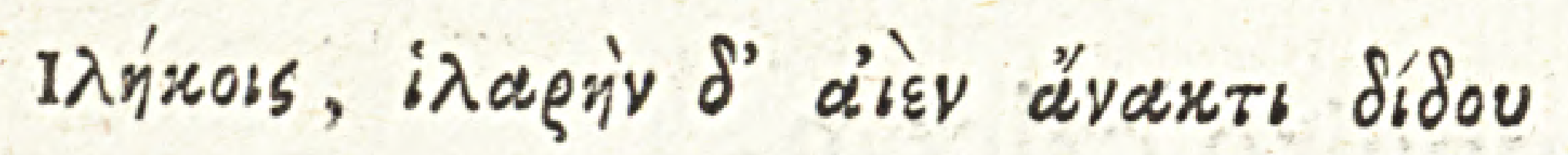

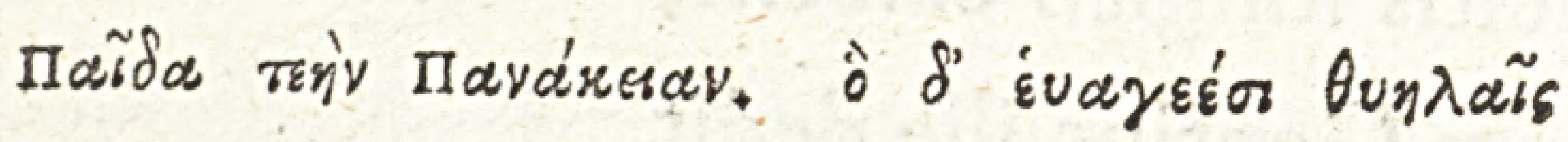

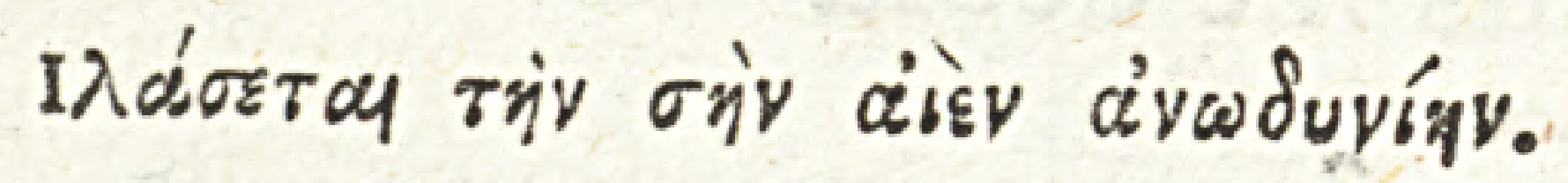


Anifum, fuccum de preffa Hypociftide, fruetum

Balfami, ut et gummi gluten amansque, tenax. Fœniculi femen, Cardamomumque quod Ida

Protulit, et Sefelin fquallidam ad ifta dabis. Lacruma fubfufci fpina crefcente coloris

Omnibus æqualis portio Thlafpis erit.

Hyperici tantum, tantum Ammeos adiicis ergo,

Et Sagapenus item res ea quarta, trahat.

Accedantque tui gemini fimul Iftrice Caftor

Teftes, pertenuis fibraque Ariftolochi.

Ordine fupremo fint Dauci femina; ficcum

Alphaltum multum contra venena valens.

Sit Panacis fucco pondus Centaurion æquim,

Galbanus atque tenax claudat ut agmen, item.

Quæ tamen huc intrant emolliat humida vinum

Antiquum, fluidum, lacruma fiue foret.

At contufa dein folerter ficca, relinques

Melli, quod iuxta littora condit apis.

lamque faue felix, qui pandis talia Pron,

Te genium Triccæ fiue cacumen alat,

Siue Rhodos, Burrina fimulque Epidaurus adorent,

Commendans Domino munera tanta, veni,

Inuentam fobolem panaceam, litet is aris

Si careat trifti vita dolore, Tuis. 


\section{Annectitur cuius p. 18. mentio fie}

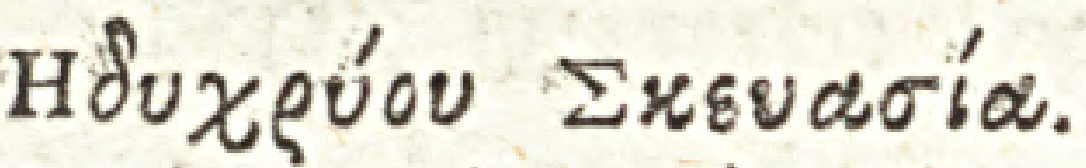

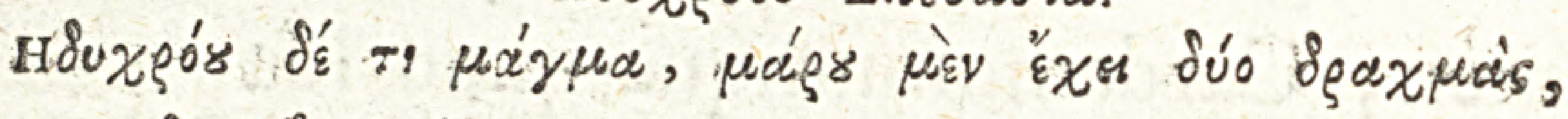

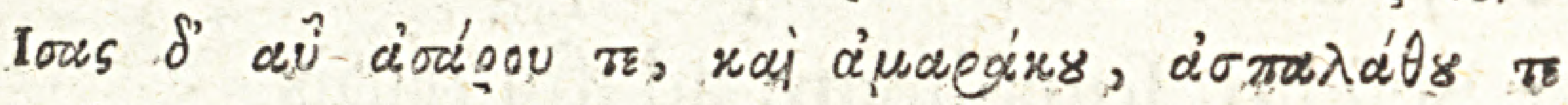

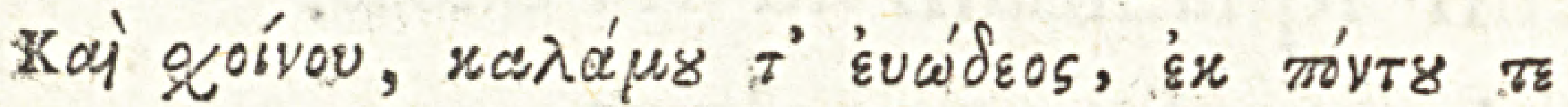

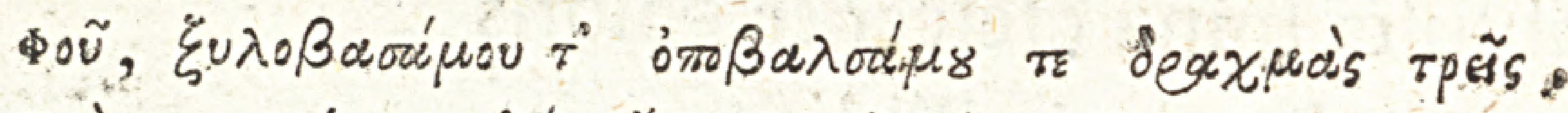

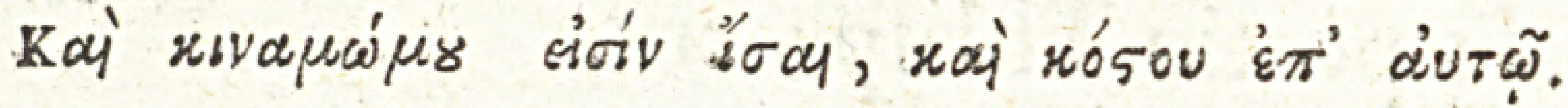

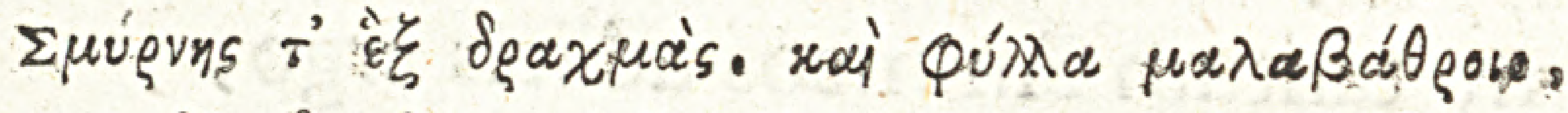

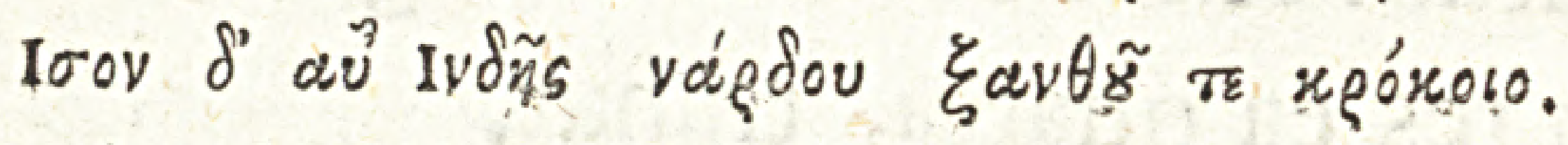

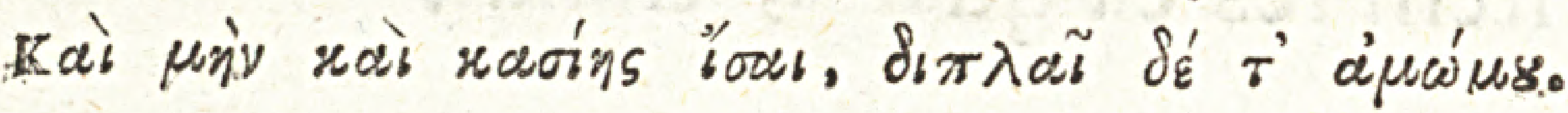

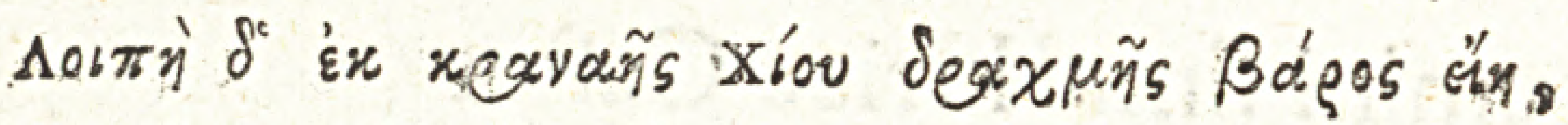

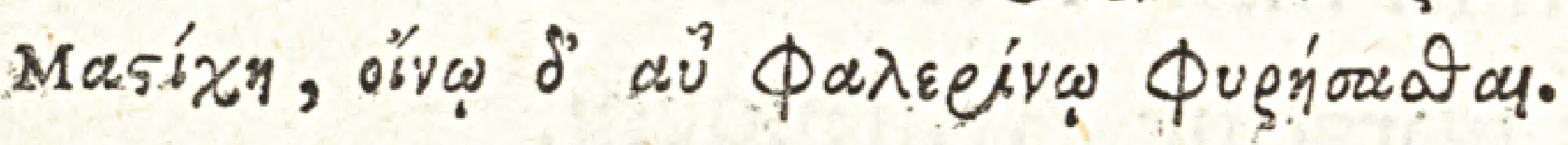

Hedychroi qui forte velit componere dictum Magma, Mari drachmas fumpferit ille duas, Æquales inter fuccedat Amaracus illas,

Sinc Afari partes Afpalathique pares, Tunc Iunci graciles, Calami fragrantis odoris, Phu fimul e terris aduena, Ponte, tuis. Balfama de ligno, fuccoque fluentia demum, Singula fint drachmis adiicienda tribus. Tres habeat Coftus; tot promant Cinnama rara Sex alias fecum Myrrháque rubra terat. Tot Malabathra fuis foliis ac indica Nardus Tot drachmas flauus pofcit habere Crocus. Tot capis et Cafiæ, duplum confueuit Amomi; Vnius drachmæ Maftiche Chia fequi. $\mathrm{H} x \mathrm{c}$ inter fe quis mira confuderit arte Viribus irrorent vina falerna fuis. 